\title{
Indian College of Radiology and Imaging Evidence-Based Guidelines for Percutaneous Image-Guided Biliary Procedures
}

\author{
${ }^{1}$ Department of Radiodiagnosis and Interventional Radiology, All \\ India Institute of Medical Sciences, Delhi, India \\ ${ }^{2}$ Department of Radiology, Sree Chitra Tirunal Institute of Medical \\ Sciences and Technology (Thiruvananthapuram), Kerala, India \\ ${ }^{3}$ Department of Radiology, Christian Medical College (Vellore), \\ Tamil Nadu, India \\ Indian J Radiol Imaging 2021;31:421-440.
}

Kumble Seetharama Madhusudhan ${ }^{1}$ Valakkada Jineesh ${ }^{2, \odot} \quad$ Shyamkumar Nidugala Keshava ${ }^{3, \odot}$

\author{
Address for correspondence Dr. Kumble S. Madhusudhan, \\ MD, FRCR, Department of Radiodiagnosis, All India Institute \\ of Medical Sciences, Ansari Nagar, New Delhi 110029, India \\ (e-mail: drmadhuks@gmail.com).
}

\begin{abstract}
Keywords

- biliary drainage

- percutaneous transhepatic biliary drainage

- malignant biliary strictures

- benign biliary stricture

- guidelines

Percutaneous biliary interventions are among the commonly performed nonvascular radiological interventions. Most common of these interventions is the percutaneous transhepatic biliary drainage for malignant biliary obstruction. Other biliary procedures performed include percutaneous cholecystostomy, biliary stenting, drainage for bile leaks, and various procedures like balloon dilatation, stenting, and large-bore catheter drainage for bilioenteric or post-transplant anastomotic strictures. Although these procedures are being performed for ages, no standard guidelines have been formulated. This article attempts at preparing guidelines for performing various percutaneous image-guided biliary procedures along with discussion on the published evidence in this field.
\end{abstract}

\section{Introduction}

Percutaneous image-guided biliary procedures are the common nonvascular radiological interventions performed in the management of various benign and malignant pathologies of the biliary system. The commonly performed biliary interventions are percutaneous transhepatic biliary drainage (PTBD), biliary stenting (BS), and percutaneous cholecystostomy (PC). Other procedures include performing PTBD in postoperative bile leaks and various treatment procedures in benign postoperative biliary strictures, like bilioenteric and post-liver transplant anastomotic strictures. These procedures are safe and effective, particularly if appropriate steps are followed while performing them. Hence, formulating suitable guidelines based on the current published evidence and recommending them accordingly is necessary.

\section{Methods}

The Indian College of Radiology and Imaging (ICRI), after recognizing the necessity of framing these guidelines, adhered

published online

July 28, 2021
DOI https://doi.org/ $10.1055 / \mathrm{s}-0041-1734222$ ISSN 0971-3026 to the following process. The Interventional Radiology subspecialty head of the ICRI along with the committee identified an expert in the field to serve as the principal author. The principal author was allowed to assign other experts in the field as deemed necessary. The prospective authors performed extensive literature search and framed the guidelines in the form of statements and assigned the grade of recommendation ( $1=$ strong, $2=$ weak) and quality of evidence $(\mathrm{A}=$ high, $\mathrm{B}=$ moderate, $\mathrm{C}=\mathrm{low}$ ) as defined by UpToDate grading guide [https://www.uptodate.com/home/ grading-guide].

The guidelines with the grade of recommendations were then reviewed by the committee of ICRI along with the interventional radiology subspecialty head. The draft was finalized after incorporating the comments of the committee. The statements and discussions have been broadly divided into two parts: Part 1 discussing the preprocedure evaluation and Part 2 discussing the details of various biliary procedures.

\section{(c) 2021. Indian Radiological Association.}

This is an open access article published by Thieme under the terms of the Creative Commons Attribution-NonDerivative-NonCommercial-License, permitting copying and reproduction so long as the original work is given appropriate credit. Contents may not be used for commercial purposes, or adapted, remixed, transformed or built upon. (https://creativecommons.org/licenses/by-nc-nd/4.0/).

Thieme Medical and Scientific Publishers Private Ltd. A-12, Second Floor, Sector -2, NOIDA -201301, India 


\section{Guidelines}

\section{Summary}

\section{Part 1: Preprocedure evaluation}

\subsection{Clinical presentation of patients requiring biliary drainage}

1. The common presenting symptoms are jaundice and pruritus, recurrent fever due to cholangitis, and abdominal pain (IA).

2. Patients with post-traumatic bile leak present with increasing bile output in the drain (1B).

3. Patients with benign biliary strictures, may be asymptomatic with altered liver function tests and /or present with episodes of suspected cholangitis (1A).

\subsection{Investigations required prior to performing biliary drainage}

4. Laboratory investigations needed before biliary drainage include liver function tests, renal function tests, hemoglobin, prothrombin time, international normalized ratio (INR), and platelet count (1A).

5. Imaging is necessary with either computed tomography (CT) scan or magnetic resonance imaging (MRI) (1A).

6. Ultrasonography alone may be sufficient in cases of biliary stone disease (1B).

\subsection{Management options of patients requiring biliary drainage}

7. The approaches commonly used for biliary drainage are endoscopic and percutaneous. Endoscopic drainage is performed for mid and lower bile duct obstructions and PTBD is performed for high or hilar obstruction. PC is an option in nondilated bile ducts with lower bile duct obstruction. Surgical drainage is rarely performed, especially during a definitive treatment procedure for the cause of obstruction (1A).

8. Antibiotics are necessary in patients with cholangitis $(1 \mathrm{~A})$.

\section{Part 2: Interventional radiology management}

\subsection{Indications and contraindications}

9. Common indications for PTBD include (a) Malignant hilar biliary obstruction; (b) Clinical features of cholangitis; (c) Postoperative bile leak; (d) Benign biliary strictures; (e) Failed endoscopic drainage; (f) Removal of calculi; (g) Cases where endoscopy is not possible due to altered anatomy after surgery (1A).

10. There are no absolute contraindications for biliary drainage. The relative contraindications for biliary drainage are (a) Deranged coagulation parameters; (b) Ascites; (c) Poor performance status; (d) Stage IV malignant disease (1A).

11. Indications for PC are: (a) Acute cholecystitis with sepsis or with surgical comorbidities; (b) obstructive jaundice with cholangitis due to common duct block where ERCP or PTBD is not feasible; (c) as an access route for biliary interventions (1A).

12. Contraindications for $P C$ are relative and include deranged coagulation parameters and ascites ( $1 \mathrm{~A})$.

\subsection{Patient preparation prior to biliary procedures}

13. Patients should be fasting for 4-6 h prior to the procedure (1A).

14. Adequate hydration should be maintained (1C).

15. Broad spectrum antibiotics should be administered prior to the procedure and continued for $3-5 d(1 \mathrm{~A})$.

16. Ascites, when present, should be drained (1A).

\subsection{Procedure of PTBD}

17. Initial puncture of the bile duct should be preferably performed under ultrasonography (USG) guidance (1A).

18. Subsequent steps follow Seldinger technique under fluoroscopy (1A). Bedside PTBD is performed completely under USG guidance with external drainage (1B).

19. Unilobar drainage is usually adequate. Other lobe is drained if the bilirubin is persistently high or when there is cholangitis (1B).

20. Either right- or left-sided approach may be chosen if there are no contraindications to drain a lobe (1B).

21. Biliary stent is preferred over catheter in malignancies for palliation (1A).

\subsection{Procedure of percutaneous cholecystostomy}

22. PC should be performed under ultrasonography guidance, either through direct peritoneal or transhepatic routes, bed side or in interventional suite $(1 \mathrm{~A})$.

23. Both Seldinger and trocar techniques may be used (1B).

\subsection{Expected outcomes of PTBD}

24. There is decrease in serum bilirubin values, thereby preparing the patient for surgery or chemotherapy whichever is appropriate; reduction or resolution of cholangitis, pain and pruritus (1A).

25. There is decrease in the bile output in the surgical drainage catheter (1B). 


\subsection{Complications of PTBD and their management}

26. Most common major complication is cholangitis. It is treated with antibiotics, uncapping the internal/external drainage catheter, repositioning the displaced catheter, exchange or upgradation of the drainage catheter and /or draining the undrained system (1A).

27. Abdominal pain is another common complication, managed by analgesics (1A).

28. Pericatheter leak is managed by repositioning a displaced catheter, upgrading the catheter, draining ascites when present, and placing a stoma bag (1B).

29. Catheter-related complications include partial or complete displacement or fracture of catheter. They are managed by repositioning the catheter, replacing the catheter through the previous tract or performing a new procedure immediately or later depending on the extent of biliary dilatation and urgency of the drainage (1B).

30. Hemorrhagic complications present in the form of bleeding from or around the catheter, hematemesis or melena or hypotension and shock. They are managed, depending on the severity, by capping the catheter for tamponade, doing cholangiogram or CT angiography followed by digital subtraction angiography (DSA) and embolization wherever necessary (1A).

31. Pancreatitis is an uncommon complication. It is managed similar to acute pancreatitis occurring due to other etiologies (1B).

\subsection{Follow-up of patients of PTBD}

32A. Regular clinical evaluation should be done by evaluating patient's performance status, jaundice, and fever (1B).

32B. Laboratory parameters like serum bilirubin and alkaline phosphatase should be regularly done (1B).

32C. Ultrasonography and/or cholangiogram, should be performed whenever necessary (1B).

32D. Catheter exchanges must be done at regular intervals (1B).

\subsection{Complications and outcomes of percutaneous cholecystostomy}

33. Common complications include catheter displacement, bile leak, biliary peritonitis, and hemorrhage. Management is by repeat procedure, catheter replacement, drainage, and embolization. (1B)

34. The aim of PC is relief of acute symptoms and infrequently, biliary obstruction (1B).

\subsection{Indications for biliary stenting}

35. Malignant biliary obstruction is the most common indication, particularly in the palliative setting (1A).

36. The role of stents in benign biliary strictures is not well established (1B).

\subsection{Types of biliary stents and their indications}

37. The widely used stent for malignant biliary obstruction is uncovered self-expandable metallic stent; covered stents are still not routinely recommended for malignant biliary obstruction (1A).

38. Metallic stents are always better than plastic stents for malignant strictures (1B).

39. Retrievable covered stents are promising in benign biliary strictures (1B).

40. Bioabsorbable stents are used in research settings, particularly in benign strictures (1B).

41. The role of drug eluting stents is not established (1C).

\subsection{Biliary stenting technique in malignant biliary obstruction}

42. Both one-stage and two-stage deployment of the stents can be done (1B).

43. Between suprapapillary and transpapillary stent placement neither has distinctly shown benefit over the other (1B).

44. Bilobar stents may be stent-in-stent or parallel stent and in T or Y configuration (1B).

\subsection{Technique for PTBD in benign strictures or bile leaks}

45. Benign strictures and bile leaks are associated with minimally dilated or nondilated bile ducts which increase the difficulty of the procedure and complications; there is no difference in the procedural steps of PTBD (1B).

46. Benign strictures are managed by balloon dilatation, serial upgradation to large bore catheters and stents (1B).

47. Endoscopic stenting is the preferred option in case of biliary strictures or bile leaks in post-transplant patients; if endoscopic attempt is unsuccessful or there is altered anatomy (bilioenteric anastomosis), percutaneous biliary drainage is the next option (1B).

\subsection{Brush cytology or brush biopsy in malignant biliary strictures}

48. Intrabiliary brush cytology or biopsy should be obtained whenever possible, particularly when other methods of tissue sampling are not possible or fail (1B).

\subsection{Current status of intrabiliary treatment techniques for malignant strictures}

49. Intrabiliary radiofrequency ablation (RFA) has been shown to increase patency rates of biliary stent and may be used (1B).

50. Intrabiliary radiation therapy improves patency of the stent and patient survival (1C). 


\subsection{Other methods of biliary drainage and their indications}

51. Other methods of biliary drainage include endoscopic drainage, surgical drainage, and endoscopic ultrasound-assisted drainage (1A).

52. Endoscopic drainage is suggested as the initial choice in cases of mid and lower bile duct obstruction with normal upper gastrointestinal anatomy (1A).

53. Endoscopic ultrasound-assisted drainage is increasingly being used, but its role is yet to be established (1B).

54. Surgical drainage is indicated in patients who fail minimally invasive procedures or who need definitive treatment (1A).

\section{Detailed Guidelines}

\section{Part 1: Preprocedure Evaluation}

1.1. Clinical presentation (signs/symptoms/when to suspect)

Q1. What are the common clinical presentation of patients requiring biliary drainage?

The most common symptoms are obstructive jaundice and pruritus, recurrent fever due to cholangitis, and abdominal pain (1A).

\section{Remarks}

Jaundice is the most common presentation of biliary obstruction. Even though most causes of obstructive jaundice are benign in nature, the common indications for biliary drainage procedure are due to malignant lesions producing biliary obstruction. ${ }^{1}$ In malignant causes, periampullary carcinoma is the most common, followed by hilar cholangiocarcinoma. ${ }^{1,2}$ In addition to jaundice, patients may present with pruritus which occurs in 50 to $80 \%$ of malignant cases. ${ }^{3}$ Abdominal pain occurs in majority of benign cases, while in malignancy it is seen in 50 to $60 \%$ and occurs late. ${ }^{1,3}$ Cholangitis occurs in both benign and malignant cases and presents with fever and can complicate into sepsis and multiorgan failure.

Q2. How do patients of post-traumatic bile leak manifest?

Patients with post-traumatic bile leak present with increasing bile output in the drain (1B).

\section{Remarks}

Post traumatic bile leak occurs after laparoscopic cholecystectomy (0.3-0.5\%), open cholecystectomy, liver resection (3-11\%), and liver transplantation (LT) (4-5\%). ${ }^{4}$ It should be suspected when there is persistent bile in drainage catheter, abdominal distention or with features of biliary peritonitis, in the postoperative period. ${ }^{5}$ Liver transplant recipients may present with early and delayed biliary leak due to biliary ductal injury and also due to hepatic arterial thrombosis. Patients with grades 3 to 5 blunt liver injury frequently present with biliary leak after 5 to 6 days of trauma which require a drainage procedure.

Q3. What are the symptoms of patients with benign biliary strictures?

Patients with benign biliary strictures, may be asymptomatic with altered liver function tests and /or present with episodes of suspected cholangitis (1A).

\section{Remarks}

In patients with benign biliary strictures, other than the obstructive symptoms, the patients may be asymptomatic with altered liver function tests in the form of elevated alkaline phosphatase and gamma-glutamyl transferase. ${ }^{6}$ The causes include post cholecystectomy or post LT biliary stricture or bilioenteric anastomotic stricture. They can also present with recurrent episodes of cholangitis and may progress to biliary cirrhosis if not diagnosed early. ${ }^{7}$

1.2. Investigations required (laboratory and imaging)

Q4. What laboratory investigations are required from patients prior to performing biliary drainage?

Laboratory investigations needed before biliary drainage include liver function tests, renal function tests, hemoglobin, prothrombin time, INR, and platelet count (1A).

\section{Remarks}

Liver function tests with prothrombin time and INR are required in all cases prior to any hepatic interventional procedure. Like in a general surgical procedure, hemoglobin needs to be ideally above $10 \mathrm{~g} / \mathrm{dL}$, and hemoglobin levels below $6 \mathrm{~g} / \mathrm{dL}$ require packed red-blood cell transfusion. ${ }^{8,9}$ In patients with hemoglobin levels between 6 and $10 \mathrm{~g} / \mathrm{dL}$, the decision of transfusion depends on hemodynamic condition of the patient. ${ }^{9}$ Platelet count is required in all patients and counts below $50,000 / \mathrm{mL}$ require platelet transfusion. ${ }^{10,11}$

Q5. What imaging modalities are necessary before biliary drainage?

Imaging is necessary with either CT scan or MRI (1A).

\section{Remarks}

The main aims of imaging are to assess the cause and level of obstruction, and stage the disease. Imaging with either CT scan or MRI is necessary in almost all patients prior to biliary drainage. ${ }^{12,13}$ In the diagnosis of malignant hilar stricture, accuracy of CT scan and MRI is comparable, although, CT scan shows the vascular involvement better while MRI better depicts biliary tree. ${ }^{14}$ Magnetic resonance cholangiopancreatography (MRCP) provides a better delineation of the bile ducts than $\mathrm{CT}$, and is comparable to ERCP. ${ }^{15}$ A study comparing MRI with MRCP and CT in periampullary tumors showed that MRI with MRCP is better than CT scan with AUROC of 0.96 and 0.81 , 
respectively.$^{16}$ The MRI is better than CT or ultrasonography (USG) in cases of bilioenteric anastomosis stricture, benign inflammatory strictures like primary sclerosing cholangitis, and recurrent pyogenic cholangitis. ${ }^{17-19}$

Q6. How does ultrasonography assist in preprocedure diagnosis?

Ultrasonography alone may be sufficient in cases of biliary stone disease (1B).

\section{Remarks}

Ultrasonography alone may be sufficient in cases of biliary stone disease. It is used as screening modality in suspected malignant biliary lesions which later require a cross sectional imaging for staging and operability. ${ }^{1}$ USG is used to assess biliary dilatation, ascites, liver volume, and patency of biliary confluence, all of which are critical in planning the drainage procedure. ${ }^{13,20}$

\subsection{Management (Medical/IR/other)}

Q7. What are the management options of patients requiring biliary drainage?

The approaches commonly used for biliary drainage are endoscopic and percutaneous. Endoscopic drainage is performed for mid and lower bile duct obstructions and PTBD is performed for high or hilar obstruction. Percutaneous cholecystostomy is an option in nondilated bile ducts with lower bile duct obstruction. Surgical drainage is rarely performed especially during a definitive treatment procedure for the cause of obstruction (1A).

\section{Remarks}

Endoscopic biliary drainage (EBD) is attempted for mid and distal obstruction. A systematic review and meta-analysis comparing EBD and PTBD in periampullary carcinoma found that EBD is safer and has lesser tumor seeding rate compared with PTBD. ${ }^{21}$ However, in cases of failure of the endoscopic approach, PTBD should be performed as an emergency since endoscopy, not being an aseptic procedure, is likely to increase the risk for cholangitis. In hilar masses, EBD needs more expertise and has higher risk of cholangitis due to contamination from duodenal contents. The DRAINAGE trial, meta-analysis by Moole et al, and by Tang et al, have shown higher technical success and lower incidence of cholangitis with PTBD for hilar cholangiocarcinoma; however, there was more patient discomfort and catheter-related complications. ${ }^{22-24}$ In another meta-analysis by Liu et al, in resectable hilar masses, PTBD had better success rates with less infection rate compared with EBD and so PTBD was recommended in hilar lesions. ${ }^{25}$ In lower bile duct obstruction, the peripheral intrahepatic biliary radicals may not be dilated and percutaneous puncture of biliary radical may come difficult even with repeated attempts. ${ }^{26}$ In such cases PC may be attempted. ${ }^{27}$

Q8. What is the role of antibiotics in cholangitis?

Antibiotics are necessary in patients with cholangitis (1A).

\section{Remarks}

Patients in cholangitis have an increased mortality rate, with a 30 day "all-cause mortality rate" of approximately $10 \%{ }^{28}$ Hence, such patients should be treated with antibiotics within one hour of onset of fever and hypotension in cases of septic shock and within six hours of diagnosis in others. ${ }^{29,30}$ Empirical antibiotics like ampicillin/sulbactam can be used as initial therapy. ${ }^{28}$

\section{Part II: IR Management}

\subsection{Indications and contraindications}

Q9. What are the indications for PTBD?

a. Malignant hilar biliary obstruction.

b. Clinical features of cholangitis.

c. Postoperative bile leak.

d. Benign biliary strictures.

e. Failed endoscopic drainage.

f. Removal of calculi.

g. Cases where endoscopy is not possible due to altered anatomy after surgery.

Level of evidence-1A

\section{Remarks}

Biliary drainage in malignant resectable cases is performed to reduce the bilirubin levels and improve liver function. PTBD is usually not recommended in operable, noncomplicated periampullary mass, if the bilirubin is below $10 \mathrm{mg} / \mathrm{dL}$ in view of procedure-related complications which reduce a good surgical outcome. ${ }^{31,32}$ If neoadjuvant chemotherapy is required, the bilirubin levels need to be decreased to less than 2 to $5 \mathrm{mg} / \mathrm{dL}$ for adequate functioning of the various chemotherapeutic drugs. ${ }^{33}$ Biliary drainage in unresectable malignancies is mainly performed to prepare patient for palliative chemotherapy, reduce intractable pruritus, cholangitis, access for brachytherapy, and improve the quality of life..$^{12,34-36}$ In perihilar mass, since there is partial hepatectomy involved, the target bilirubin threshold is lower and so presurgical PTBD is indicated to reduce bilirubin levels to 2 to $3 \mathrm{mg} / \mathrm{dL}^{37,38}$ Cholangitis warrants urgent biliary decompression..$^{28,35,39-41}$ Elevated bilirubin with signs of systemic toxicity should be treated as cholangitis unless proven otherwise. In elderly and malnourished, fever may not be prominent and so elevated total leucocyte counts, erythrocyte sedimentation rate, and C-reactive protein are taken as markers of sepsis. ${ }^{42}$ In postoperative biliary leak, the preferred approach is endoscopic or surgical after the drainage of symptomatic biloma, if present. ${ }^{5,43,44}$ Percutaneous biliary drainage is performed if endoscopy fails or is contraindicated or in cases of intrahepatic biliary injury with biloma. ${ }^{44,45}$ The biliary system is nondilated in a majority of such cases and PTBD needs expert hands. In bilioenteric anastomotic strictures, higher adhesions around the anastomotic site make the field hostile for surgeons, and hence PTBD with balloon dilatation is the preferred option to prevent recurrent cholangitis and late liver atrophy ${ }^{46,47}$ In surgeries 
which alter the upper gastrointestinal tract anatomy, like Roux-en-Y anastomosis and Billroth procedure, standard endoscopic access to the bile ducts is limited, unless surgeon deliberately places an anterior abdominal pouch. ${ }^{48} \mathrm{In}$ such cases, percutaneous or enteroscopy or EUS-guided options assist in biliary access.

Q10. What are the contraindications of PTBD?

a Absolute contraindications-none.

b. Relative contraindications:

i. Deranged coagulation parameters

ii. Ascites

iii. Poor performance status

iv. Stage IV malignant disease

Level of evidence-1A

\section{Remarks}

PTBD is a procedure with "significant risk" of bleeding. ${ }^{11}$ There are no absolute contraindications for PTBD. ${ }^{49}$ However, there are multiple precautions which need to be taken while performing a safe procedure. The coagulation profile should be reasonably good. The INR should be ideally below 1.5. ${ }^{12,50}$ There are new recommendations suggesting an INR of below 1.7 as cut-off for a safe biliary procedure. ${ }^{3,10}$ Gupta et al, has shown less complication rates with PTBD in cases with deranged INR. ${ }^{51}$ In elective cases with deranged INR, oral vitamin $\mathrm{K}$ (5-10 mg) should be administered for 3 days in adults and then reviewed..$^{11,12}$ In emergency cases, fresh frozen plasma (FFP) is infused for immediate correction. The FFP infusion should be started prior to the procedure and continued through the procedure.,52 Prothrombin concentrates are also recommended to restore coagulopathy in acute cases. ${ }^{52,53}$ Platelet count should be above 50,000/mL. . $^{39,40,54-56}$ Platelet rich plasma transfusion should be done if counts are less than 50,000.5 One unit of random donor platelet increases platelet count by around $6,000 / \mathrm{mL}$ and one unit of single donor platelet, by around $30,000 / \mathrm{mL}^{57}$ Ascites is a relative contraindication. ${ }^{12,40,50}$ Ascites increases the risk of hemoperitoneum, and causes difficulty in tracking the dilators and catheters with increased chance of catheter malposition. Patel et al, showed higher rate of complications in the presence of diffuse ascites (26\%) compared with the presence of perihepatic fluid (7.3\%) only..$^{58}$ Ascites needs to be drained completely prior to the procedure. However, Sofue et al, successfully placed percutaneous biliary stents in 16 patients with massive ascites with coil embolization of the track..$^{59}$ There are studies showing that ascites is not a contraindication in case of cholecystostomy. ${ }^{60}$

\section{Q11. What are the indications for PC?}

Acute cholecystitis with sepsis or with surgical comorbidities; obstructive jaundice with cholangitis due to common duct block where ERCP or PTBD are not feasible; as an access route for biliary interventions $(\mathbf{1 A})$.

\section{Remarks}

The most common indication for PC is acute calculous cholecystitis, occurring in individuals with high surgical risk. ${ }^{61-63}$ A study by Akyürek et al, found that PC followed by early cholecystectomy resulted in significantly early improvement and shorter hospital stay compared with conservative management and delayed cholecystectomy. ${ }^{64}$ The authors concluded that PC assists in resolution of sepsis and prepares patient for early cholecystectomy. Similar results were found by another study by Narayanan et al. ${ }^{65}$ In a randomized controlled trial (RCT) by Hatzidakis et al, in 2002, the authors found that, in high-risk patients, PC was not better than conservative management in terms of clinical improvement and 30-day mortality. ${ }^{66}$ However, they suggested to perform PC in patients who fail to respond to conservative treatment within 3 days. Interestingly, a recent multicenter RCT from Netherlands (CHOCOLATE trial), comparing PC with laparoscopic cholecystectomy in high-risk patients with acute calculous cholecystitis, showed that PC was associated with significantly higher rate of major complications (65 vs. $12 \%) .{ }^{67}$ Ito et al, found that PC is significantly better than gallbladder aspiration in patients of acute cholecystitis in terms of technical success and clinical response with no difference in complications. ${ }^{68}$ Two large retrospective studies also found that PC was associated with higher mortality and did not offer any advantage over emergent cholecystectomy in acute cholecystitis. ${ }^{69,70}$ Hence, they suggested that PC should not be routinely used. Other indications include acute cholangitis, gallbladder mucocele, or biliary obstruction and biliary interventions (stenting or stone removal) when ERCP or PTBD is not possible or has failed. ${ }^{26,27}$ It is important to understand that PC benefits the patients with obstruction below the level of cystic duct insertion. Li et al, found that PC for acute cholangitis in high-risk patients significantly improved the clinical symptoms in $91 \%$ and had a 30-day mortality of $9 \% .{ }^{71}$ Gallstone removal through transcholecystic route is technically successful in 85 to $94 \%$ cases with low rate of complications. ${ }^{72,73}$

\section{Q12. What are the contraindications for PC?}

There are no absolute contraindications. Relative contraindications include deranged coagulation parameters and ascites (1A).

\section{Remarks}

There are no absolute contraindications for PC. ${ }^{74}$ Relative contraindications include coagulopathy, ascites, and gallbladder filled with calculi. ${ }^{60,61,74}$ Duncan et al, in their study, did not find any significant difference in complications after PC between patients with and without ascites. ${ }^{61}$ Similarly, another study comparing PC in patients without and with coagulopathy (INR >1.5; platelet count < $50 \times 10^{9} / \mathrm{L}$ ) found that there was no significant difference in the incidence of complications. ${ }^{75}$ 


\subsection{Patient preparation prior to the procedure.}

Q13. How long should the patients fast prior to biliary procedures?

Patients should be fasting for 4 to 6 hours prior to the procedure (1A).

\section{Remarks}

Patient should be kept fasting for 4 to 6 hours prior to the procedure. ${ }^{40}$ Since some of the patients may require conscious sedation, American Society of Anaesthesiology recommends at least 2 hours of fasting for clear fluids and 6 hours for light meal prior to the procedure to avoid the risk of aspiration during sedation. ${ }^{76,77}$

Q14. How should hydration be maintained?

Adequate hydration should be maintained (1C). No data are available on the protocol.

\section{Remarks}

Adequate hydration needs to be maintained by intravenous fluids since patients often suffer from inadequate nutrition and fluid imbalance resulting in low intravascular volume making them vulnerable to any episode of pain-induced vasovagal shock or inadvertent bleeding during procedure. ${ }^{12}$ Although no data are available, patients are usually infused with approximately $500 \mathrm{~mL}$ of fluids intravenously prior to the procedure.

Q15. What is the protocol for the administration of antibiotics?

Broad spectrum antibiotics should be administered prior to the procedure and continued for 3 to 5 days $(\mathbf{1 A})$.

\section{Remarks}

Prophylactic antibiotics should be given 1 hour prior to the procedure in patients without cholangitis. ${ }^{78}$ The SIR guidelines recommend prophylaxis with ceftriaxone $1 \mathrm{~g}$ or ampicillin/sulbactam intravenously prior to fresh puncture and catheter exchanges. ${ }^{79}$ In patients with cholangitis, broad spectrum antibiotics should be administered during the complete episode of cholangitis as mentioned vide supra. ${ }^{29}$

Q16. Should ascites be drained prior to the procedure?

Ascites, when present, should be drained to reduce the incidence of complications (1A).

\section{Remarks}

As mentioned previously, ascites is a relative contraindication due to the increased risks of bleeding and difficulties in catheter manipulation and warrants complete drainage prior to the procedure. ${ }^{12,50,58}$ Antiplatelet drugs like aspirin and clopidogrel preferably need to be withheld for at least 5 days prior to the procedure since it doubles the bleeding risk. ${ }^{80}$

\subsection{Basic procedure of PTBD}

Q17. Under what imaging guidance should the bile duct be punctured?
Initial puncture of the bile duct should preferably be performed under USG guidance (1A).

\section{Remarks}

The initial puncture can be done under USG or fluoroscopic guidance depending on the individual's preference and institute protocol. ${ }^{12,81}$ USG guided puncture is suggested to reduce procedure time, radiation dose, and the amount of use of contrast agent. ${ }^{82}$ However, in a recent study by Nennstiel et al, comparing fluoroscopic and USG-guided PTBD, the authors found that overall procedure success, complication rates, fluoroscopy times, and procedure times were not significantly different between the groups. ${ }^{83}$ However, in this study, fluoroscopic PTBD ( $n=207)$ was mostly done on the right side and USG guidance $(n=44)$ was mostly used for the left. Further, the numbers were not comparable. Wagner et al, found that USG-guided PTBD resulted in lower incidence of complications compared with fluoroscopic PTBD. ${ }^{84}$ The EFSUMB guidelines in 2016, recommended the use of USG for initial duct puncture with $100 \%$ consensus ${ }^{85}$ After initial puncture, remaining steps are performed under fluoroscopy. However, when the procedure is performed bedside, it is done completely under USG guidance.

Q18. What technique should be followed for steps after puncture?

Subsequent steps should follow Seldinger technique under fluoroscopy (1A). Bedside PTBD is done completely under USG guidance with external drainage (1B).

\section{Remarks}

The procedure is performed using the standard Seldinger technique after the initial puncture under fluoroscopy. ${ }^{12,81}$ If the obstruction is crossed, an 8F-sized ring biliary catheter for combined internal and external drainage is placed. If not, an $8 \mathrm{~F}$ external biliary catheter is placed and manipulation is tried few days later. When performing a bedside procedure, fluoroscopy and internalization are not possible and hence the procedure is performed under USG guidance and an external drainage catheter is placed. ${ }^{51}$

Q19. Should the drainage of one or both lobes be performed?

Unilobar drainage is usually adequate. Other lobe is drained if the bilirubin is persistently high or when there is cholangitis (1B).

\section{Remarks}

In patients with hilar obstruction, unilobar drainage is adequate to improve the liver functions. It has been suggested that drainage of $25 \%$ of the liver is sufficient to relieve symptoms of biliary obstruction, improve biochemical parameters, and reduce biliary dilatation on USG.${ }^{86}$ Hence, it is reasonable to perform unilobar drainage in cases of Bismuth II and III strictures. ${ }^{87,88}$ Inal et al, found that the clinical response, complications, and stent patency were similar in unilobar and bilobar drainage groups in cases of Bismuth II and III strictures. ${ }^{88}$ However, in type IV strictures, they suggested bilobar drainage only to improve patency of stents. Longer patency by using bilateral stents 
was also shown in other studies. ${ }^{89,90}$ Bilobar drainage has been suggested in cases of cholangitis developing after unilobar drainage and when serum bilirubin does not decrease adequately after unilobar drainage. ${ }^{91}$

Q20. Is left-sided approach better than right-sided one?

Either right- or left-sided approach may be chosen if there are no contraindications to drain a lobe (1B).

\section{Remarks}

In a patient with patent primary biliary confluence, either right or left lobe of the liver can be used to access the biliary system without any significant difference in radiation dose, procedure time, or complications. ${ }^{92,93}$ Even in cases with blocked primary confluence, absence of lobar atrophy or cholangitis and vascular invasion by the malignancy, either right- or left-sided drainage can be performed.

\section{Q21. Is biliary stent better than placement of catheter?}

Biliary stent is preferred over catheter in malignancies for palliation (1A).

\section{Remarks}

In palliative setting, biliary stent is preferred as it provides better long-term patency than catheter or plastic stents. Studies comparing plastic stents and metallic stents have shown that metallic stents have significantly longer patency rates and significantly lesser reintervention rates, but similar procedure-related complication rates. ${ }^{94,95}$ The PTBD catheter is associated with problems like early occlusion, pericatheter leakage, and partial or complete dislocation of the catheter. ${ }^{96}$ Stents are not associated with these complications. Occasionally, the percutaneous catheter may be replaced by a plastic stent over the wire. ${ }^{97}$

\subsection{Procedure of PC}

Q22. What image guidance and technique are used for PC?

PC should be done under ultrasonography guidance, either through direct peritoneal or transhepatic routes, bed side or in interventional suite (1A).

\section{Remarks}

Ultrasound guidance should be used for puncturing the gallbladder. USG is the best modality to perform PC safely and comfortably. ${ }^{98}$ Although other modalities like CT scan and fluoroscopy are occasionally used, they cannot be done bedside, are associated with radiation and increase the cost. Infrequently, after puncture under USG guidance, subsequent steps can be performed under fluoroscopy. ${ }^{99}$ CT guidance has been used in cases when gallbladder is poorly visualized on USG. ${ }^{100}$ Either transhepatic or transperitoneal route can be used to perform PC. A recent large study by Beland et al showed that there are no differences between transhepatic and transperitoneal routes in terms of pain, procedure-related complications, catheter occlusion, and catheter replacement. ${ }^{99}$ Another study comparing these techniques also found no difference in complication rate. ${ }^{101}$ It has been suggested that transhepatic route be preferred in patients with ascites and transperitoneal route in patients with liver disease or coagulopathy. ${ }^{98,102}$ Some have suggested the use of a subcostal route than an intercostal route to avoid injury to the pleura and neurovascular bundle. ${ }^{63}$

Q23. What technique should be used for PC?

Either trocar or Seldinger technique can be used for PC(1B).

\section{Remarks}

The technique used can either be trocar or Seldinger technique. No studies are available comparing the two techniques for PC. Both techniques are considered safe although Seldinger technique reduces the chances of injury due to the use of thin initial needle and trocar technique is associated with lesser steps. ${ }^{63,98}$ Many authors have suggested the use of Seldinger technique although there is no evidence to prefer one over the other. ${ }^{27,63,98}$ However, with trocar technique there is a tendency to use smaller catheter. ${ }^{99}$ Either $8 \mathrm{~F}$ or $10 \mathrm{~F}$ catheters are used for biliary drainage. Larger catheters can be used to improve drainage of thick material..$^{99}$

\subsection{Expected outcomes of PTBD}

Q24. What are the expected clinical and laboratory outcomes of PTBD?

There is decrease in serum bilirubin values, thereby preparing the patient for surgery or chemotherapy whichever is appropriate; reduction or resolution of cholangitis, pain and pruritus (1A).

\section{Remarks}

The outcome of PTBD depends on the indication for which biliary drainage is performed. Most of the procedures are performed for biliary obstruction and thus to relieve jaundice and pruritus and to improve liver function tests. Clinical success is defined as reduction of the bilirubin levels by $20 \%$ of the baseline value at the end of 1 week or by $75 \%$ at the end of 1 month after PTBD. ${ }^{87,103}$ The clinical success after PTBD ranges from 75 to $98 \%$ in the studies published. ${ }^{36,104}$ Studies have shown that the bilirubin reaches below $1 \mathrm{mg} / \mathrm{dL}$ in one-third of patients and below $2 \mathrm{mg} / \mathrm{dL}$ in up to $60 \%$ of the patients requiring chemotherapy. ${ }^{105,106}$ The decreasing bilirubin relieves the symptoms like jaundice and pruritus. The survival of the patients depends on the type and stage of the malignancy and PTBD prepares the patient for subsequent step of treatment and thus indirectly improves survival. ${ }^{104}$ In patients with cholangitis, after PTBD, success is defined when there is resolution of fever, with or without reduction in the serum bilirubin levels. ${ }^{107}$

\section{Q25. How do patients of bile leak respond after PTBD?}

There is decrease in the bile output in the surgical drainage catheter (1B).

\section{Remarks}

There is limited data on the evaluation of the outcomes of PTBD performed in the setting of bile leak. When PTBD 
is performed for bile leak, clinical success is defined as reduction of bile in the surgical drain and absence of contrast leak in the follow-up cholangiograms. ${ }^{108}$ There is no clear evidence that biliary drainage improves quality of life in patients with malignancies or biliary injury. ${ }^{106,109,110}$

\subsection{Complications of PTBD and their management}

Q26. Which is the most common complication and how is it managed?

The most common major complication is cholangitis. It is treated with antibiotics, uncapping the internal/external drainage catheter, repositioning the displaced catheter, exchange or upgradation of the drainage catheter and/or draining the undrained system (1A).

\section{Remarks}

Cholangitis is a common major complication of PTBD. The incidence of cholangitis ranges from 3 to $9 \%^{92.111-114}$ Earlier studies have shown the incidence to be 28 to $30 \% .{ }^{115,116}$ The Society of Interventional Radiology has recommended a threshold of $10 \%$ for all major complications. ${ }^{117}$ It is said that up to $85 \%$ of the patients have their bile contaminated with bacteria after initial PTBD, which increases to 100\% during later catheter exchanges. ${ }^{116}$ The diagnosis of cholangitis is based on the presence of fever and elevated total leucocyte counts. ${ }^{118} \mathrm{~A}$ definition of post-PTBD raise in temperature above 38.5 degrees for 24 hours and elevation of total leucocyte count by $20 \%$ in the absence of other evidence of sepsis has been suggested. ${ }^{119,120}$ Lucatelli et al, suggested that age, previous cholecystectomy and bilioenteric anastomotic surgery, mildly dilated or nondilated bile ducts, malignancy and unsatisfactory drainage on imaging are predictors for the development of cholangitis after PTBD. ${ }^{118}$

Management of cholangitis is initially similar to other types of cholangitis, which involves patient resuscitation, intravenous fluid supplements, and antibiotics. ${ }^{121}$ Next step is to assess the status of the biliary system and catheter to identify catheter or stent occlusion, biliary dilatation, undrained lobes or segments, displaced catheter and liver abscesses. This is done with a combination of USG or CT scan and cholangiogram..$^{91}$ Occluded catheters should be exchanged, displaced catheters may be repositioned or repeat PTBD may be performed; undrained segments require drainage through PTBD, and liver abscesses need to be aspirated or drained. ${ }^{84,85,119,121,122}$ Unclamping of the internal-external drainage catheter temporarily is also helpful. ${ }^{81,123}$ The incidence of cholangitis can be reduced by prophylactic dose of antibiotics whenever biliary procedure is performed and by regular exchange of catheters (every 2-3 months) under antibiotic cover. $84,112,124$

\section{Q27. How is abdominal pain managed?}

Abdominal pain is another common complication, managed by analgesics (1A).

\section{Remarks}

Pain is a minor complication of PTBD. Procedure-related pain is a common complication of PTBD, seen in up to $55 \%$ of patients. ${ }^{125,126}$ This occurs due to stretching of the liver capsule during initial puncture or dilatation of the tract, due to stricture dilatation and due to the presence of the catheter. The intraprocedure pain can be reduced or avoided by adequate sedation and occasionally by general anesthesia. ${ }^{127} \mathrm{~A}$ combination of midazolam and fentanyl has been shown to be effective in controlling procedure-related pain. ${ }^{128}$ Thoracic paravertebral block has also been shown to be beneficial in controlling pain during PTBD. ${ }^{129}$

Management of post procedure pain is usually by analgesics. ${ }^{125}$ They are adequate in most of the cases. Occasionally, the catheter may need to be replaced by stent or moved to a newer access location with repeat procedure.

Q28. How is pericatheter leak managed?

Pericatheter leak is managed by repositioning a displaced catheter, upgrading the catheter, draining ascites when present, and placing a stoma bag (1B).

\section{Remarks}

Pericatheter leak is a morbid complication of PTBD. It is seen in up to 33\% of patients of PTBD. ${ }^{96,112,122}$ The causes of leak include occlusion of the catheter due to sludge, clots or tumor, displacement of the catheter, pericatheter tissue necrosis and ascites. ${ }^{123}$ Management includes flushing of the catheter forcefully with warm saline, probing the catheter with hydrophilic guidewire, upgrading and/or repositioning the catheter, and replacement with internal stent and stoma bag to collect leaked bile. ${ }^{122,126}$ Bile leak may also result in perihepatic collection which requires drainage.

Q29. What are the catheter-related complications and how are they managed?

Catheter-related complications include partial or complete displacement or fracture of catheter. They are managed by repositioning the catheter, replacing the catheter through the previous tract or performing a new procedure immediately or later depending on the extent of biliary dilatation and urgency of the drainage (1B).

\section{Remarks}

Catheter displacement is an important complication, often associated with long-term indwelling. ${ }^{122}$ Partially displaced catheters should be replaced over the wire. If the catheter is fully displaced, management depends on the duration after the initial PTBD. If the catheter dislocates after approximately 10 days, a mature tract is usually formed, and it can be cannulated using a catheter and hydrophilic wire. Subsequently, a larger catheter may be inserted. ${ }^{123,126}$ If catheter dislocates earlier, then repeat procedure may be necessary. Sometimes, displacement may result in biloma formation which may need drainage if large and symptomatic. Catheter fracture is an uncommon complication, which occurs particularly when it is connected to a bag for a long time. If the fracture site is external, then the catheter should be replaced over a wire. If it is deep, then steps should be taken to remove or push the fracture fragment and replace it with new catheter. ${ }^{130}$ 
Q30. What are the manifestations and management options for hemorrhagic complications?

Hemorrhagic complications present in the form of bleeding from or around the catheter, hematemesis or melena or hypotension and shock. They are managed, depending on the severity, by capping the catheter for tamponade, doing cholangiogram or CT angiography followed by DSA and embolization wherever necessary (1A).

\section{Remarks}

Hemorrhagic complications after PTBD are uncommon but are potentially lethal. The incidence of these complications ranges from 2 to $3 \%{ }^{131}$ In a large study involving 3,110 patients by Choi et al, the incidence of severe hemorrhage was $1.9 \% .{ }^{132}$ Most common presentation is bleeding in the catheter or blood mixed with bile. Other presentations include pericatheter bleeding, gastrointestinal bleeding like hematemesis or melena, hemodynamic instability and shock. ${ }^{133}$ Delayed bleeding (after 3-7 days of PTBD) is usually due to arterial injury. ${ }^{133,134}$ Bleeding may occur into the perihepatic space and peritoneal cavity. Since PTBD is an invasive procedure, some amount of blood in the drain is normal during the initial 24 to 48 hours. ${ }^{122}$

Management of minor hemorrhage, in a hemodynamically stable patient is conservative. ${ }^{113}$ If the bleeding is persistent, cholangiogram without or with CT angiogram is necessary to identify any bleeding source. ${ }^{126}$ Venous communication on cholangiogram can be managed by temporary clamping of the catheter or upgrading the catheter. ${ }^{126}$ Occasionally, coil embolization of the vein or placement of stent graft may be necessary. ${ }^{135,136}$ Sometimes, bleeding may occur due to a malpositioned catheter with holes communicating with portal vein branches and hence may need repositioning. ${ }^{123}$ Arterial communication or arteriobiliary fistula and any pseudoaneurysm (hepatic, intercostal, or abdominal wall arteries) are treated by embolization. Angiography should be performed, preferably with the catheter removed over a wire, for better demonstration of the site of bleeding. ${ }^{137}$ The standard "sandwich technique," i.e., closure of distal and proximal openings, is used for embolization, usually with coils. ${ }^{126}$ If this is not possible, $n$-butyl cyanoacrylate glue may be used, either endovascularly or by direct percutaneous route, if the pseudoaneurysm is seen on USG. ${ }^{138}$

Q31. How common is pancreatitis after PTBD and how is it managed?

Pancreatitis is an uncommon complication. It is managed similar to acute pancreatitis occurring due to other etiologies (1B).

\section{Remarks}

Acute pancreatitis occurring after biliary intervention is an uncommon complication with a prevalence ranging from 0.48 to $6 \% .{ }^{119,126,139}$ It is defined as new onset of epigastric pain after PTBD with the elevation of serum amylase or lipase more than three times normal within 24 hours of the procedure. ${ }^{119}$ Asymptomatic hyperamylasemia is common after PTBD and is seen in up to one-fifth of the patients. ${ }^{139}$ The risk is higher whenever the distal bile duct or ampulla is manipulated as with placement of internalexternal drainage catheter or stent. ${ }^{126,139}$ Majority of them will develop mild pancreatitis. Management is similar to acute pancreatitis developing due to other etiologies.

\subsection{Follow-up of patients of PTBD}

Q32. How are patients of PTBD followed up?

- Regular clinical evaluation should be done by evaluating patient's performance status, jaundice and fever.

- Laboratory parameters like serum bilirubin and alkaline phosphatase should be regularly done.

- Ultrasonography and/or cholangiogram, should be performed whenever necessary.

- Catheter exchanges must be done at regular intervals.

Level of evidence: $\mathbf{1 B}$.

\section{Remarks}

No standard follow-up protocol has been recommended after PTBD. However, many studies have suggested that the patients with internal-external drainage catheters be reviewed every 2 to 3 months for any delayed complications and perform check of cholangiogram and catheter exchange. ${ }^{84,112}$ Patients should be evaluated clinically for improvement in jaundice and fever. Liver function tests should be evaluated once in 1 to 2 weeks to assess the clinical response of PTBD or stenting, more frequently in the initial 2 weeks. ${ }^{140}$ If the serum bilirubin is stagnant or increasing, then repeat evaluation should be done to look for any undrained segments and procedure should be performed to drain them. The patients should be advised to flush the catheters with $20 \mathrm{~mL}$ of sterile saline two to three times every day to prevent clogging of the catheter. ${ }^{112,122}$ In patients who are on external drainage, adequate hydration should be advised. In the event of any symptoms related to the procedure like fever, pericatheter leak, catheter displacement, abdominal distension or bleeding, they should be advised to visit the hospital for further evaluation according to the symptoms. If an imaging becomes necessary, USG or CT scan should be performed. MRI is occasionally necessary.

\subsection{Complications and outcomes of PC.}

\section{Q33. What are the complications of PC?}

Common complications include catheter displacement, bile leak, biliary peritonitis, and hemorrhage; management is by repeat procedure, catheter replacement, drainage, and embolization (1B).

\section{Remarks}

The incidence of complications after PC ranges from 2.4 to $16 \%{ }^{100,141}$ The complications associated with transhepatic route of PC include pain, sepsis, bleeding from the liver, biliary fistula, and pneumothorax. ${ }^{142}$ Pain can be managed by parenteral analgesics. Biliary infection is managed 
mostly with antibiotics. ${ }^{143}$ Mild bleeding usually settles on conservative management. ${ }^{27}$ Severe bleeding may need CT angiogram and embolization. Catheter dislodgement, occurring in up to $9 \%$ of the patients, may be asymptomatic or may result in bile leak which requires repeat procedure or drainage of biloma or both. ${ }^{142,144}$ Procedure-related mortality is seen in $<1 \%$ cases. ${ }^{100,145}$

Q34. What are the outcomes of PC?

The aim of PC is relief of acute symptoms and infrequently, biliary obstruction (1B).

\section{Remarks}

The response to PC, depending on the indication, is considered positive, when the symptoms resolve, the body temperature decreases to below 37.5 degrees and there is decrease in total leucocyte count by $25 \%$ within 72 hours of the procedure. ${ }^{146}$ Follow-up is done by clinical and laboratory parameters and if necessary, by imaging, usually USG. After PC, the catheter should be left in situ for at least 4 to 6 weeks to allow maturation of the tract. ${ }^{98,147}$ The catheter should be flushed with sterile saline twice a day to prevent clogging. Clogged catheters can be cleared by passing a guide wire through them or they may be replaced with newer catheters. ${ }^{98}$

2.9. Indications for BS.

Q35. What are the indications for BS?

Malignant biliary obstruction is the most common indication, particularly in the palliative setting (1A).

\section{Remarks}

Metallic stents are the standard palliative forms of treatment of malignant biliary strictures. ${ }^{148}$ Metallic stents provide better long-term patency rates compared with plastic stents in inoperable malignant strictures. ${ }^{149}$ The median patency rates are in the range of 7 to 9 months. ${ }^{150,151}$ Stenting may be unilobar or bilobar, but the former is usually adequate as described earlier for unilobar biliary drainage. ${ }^{13,87,134} \mathrm{~A}$ recent randomized controlled trial also confirmed that bilobar drainage does not offer benefit over unilobar drainage. ${ }^{152}$ Similarly, a recent meta-analysis also found that efficacy and safety of unilobar and bilobar endoscopic stenting are comparable. ${ }^{153}$

Q36. What is the role of biliary stents in benign biliary strictures?

The role of stents in benign biliary strictures is not well established (1B).

\section{Remarks}

Although, stents are not usually advised for benign biliary strictures, retrievable covered self-expandable metallic stents (SEMS) are increasingly being used with clinical success rates ranging from 75 to $90 \% .{ }^{154-156}$ Stent migration rates were 14 to $20 \%$ in these patients. In addition, biodegradable stents, which spontaneously dissolve in 3 to 6 months, are finding place in the management of benign strictures with promising results. ${ }^{157,158}$

\subsection{Types of biliary stents and their indications.}

Q37. What is the type of stent used in malignant biliary obstruction?

The widely used stent for malignant biliary obstruction is uncovered self-expandable metallic stent. Covered stents are still not routinely recommended for malignant biliary obstruction (1A).

\section{Remarks}

Various types of biliary stents available include uncovered SEMS, covered stents which may or may not be retrievable, bioabsorbable stents, and drug eluting stents. ${ }^{134,148}$ Uncovered SEMS are routinely recommended for malignant biliary strictures. Covered stents have been suggested to reduce tumor ingrowth and improve patency; however, they are associated with increased migration rates and possibility of isolation of biliary, cystic and pancreatic ducts. ${ }^{148}$ Studies comparing uncovered and covered SEMS for malignant strictures have shown no distinct advantage of covered over uncovered stent. ${ }^{151}$ This was shown in a meta-analysis of 20 randomized controlled trials. ${ }^{159}$ Another large randomized controlled study by Kullman et al showed no difference in stent patency or survival of patients between covered and uncovered SEMS. ${ }^{160}$ Absence of survival benefit with covered SEMS was also shown in a meta-analysis evaluating 2,239 patients. ${ }^{161}$ Further, since covered SEMS are expensive, it is currently recommended to use uncovered SEMS routinely.

\section{Q38. Are metallic stents better than plastic stents?}

Metallic stents are always better than plastic stents for malignant strictures (1B).

\section{Remarks}

Metallic stents are associated with longer patency rates compared with plastic stents due to their larger calibre. ${ }^{89,95,96,103,149}$ The recommended size of the metallic stent is 8 to $10 \mathrm{~mm} .{ }^{162}$ Plastic stents are typically placed endoscopically for benign conditions and preoperatively for malignant pathologies. ${ }^{22,25}$ Although, plastic stents may be exchanged when necessary endoscopically, removing a metallic stent is challenging.

Q39. What types of stents are used in benign biliary strictures?

Retrievable covered stents are promising in benign biliary strictures (1B).

\section{Remarks}

Retrievable covered stents have been successfully used in the management of benign biliary strictures. ${ }^{154-156}$ Covered stents have a larger diameter and maintain dilatation as long as they are in place. ${ }^{148,155}$ With a mean indwelling period of 6 to 12 months, these stents provide a clinical success of 75 to $90 \%$ and mean duration patency of the stricture after stent removal of 36 months. ${ }^{154-156}$ The covered stents offer significantly longer patency rates 
of benign bilioenteric anastomotic strictures compared with balloon dilatation (3-year patency 85 vs. $53 \%$ ). ${ }^{163}$

Q40. What is the current role of bioabsorbable stents?

Bioabsorbable stents are used in research settings, particularly in benign strictures (1B).

\section{Remarks}

Biodegradable stents, as described in the previous section, have shown promising results in the management of benign biliary strictures. ${ }^{157,158}$ They have been used in cases which fail standard treatment. A recent meta-analysis comparing biodegradable stents and multiple plastic stents in benign biliary strictures showed that clinical success rate was similar in both groups ( 83 vs. $84 \%$ ), but the incidence of cholangitis was higher in the plastic stent group. ${ }^{164}$

Q41. What is the status of drug eluting stents for malignant biliary strictures?

The role of drug eluting stents is not established (1C).

\section{Remarks}

Drug eluting stents, like paclitaxel coated stents, have been proposed to improve patency and survival in malignant strictures, but have not been proven in small studies evaluating its use. ${ }^{165,166}$ Hence, its use is not established.

\subsection{BS technique in malignant biliary obstruction}

Q42. Should biliary stent be deployed in one stage or two stages?

Both one-stage and two-stage deployment of the stents can be performed (1B).

\section{Remarks}

Biliary stent placement may be performed either in a single stage (primary) or in two stages (PTBD followed by stent; secondary). ${ }^{167,168}$ Both the techniques are effective. However, in view of shorter hospital stay and reduced cost, primary stenting is preferable. ${ }^{167,168}$ Predilatation of the stricture prior to stenting is not advisable. ${ }^{167}$ Although balloon dilatation prior to stenting is feasible, it has no effect on the long-term outcomes. ${ }^{169}$

Q43. Is suprapapillary stent placement better than transpapillary position?

Between suprapapillary and transpapillary stent placement neither has distinctly shown benefit over the other (1B).

\section{Remarks}

In cases with strictures involving the hila and proximal bile duct, it is not clear whether the distal end of the stent should be across the papilla or remain proximal to it. ${ }^{13,170}$ Few studies have shown that suprapapillary stenting results in reduced incidence of pancreatitis and ascending cholangitis. ${ }^{171,172}$ However, other studies have shown no significant difference between the two techniques in effectiveness and safety. ${ }^{170,173}$
Q44. How should bilobar stents be placed?

Bilobar stents may be placed as stent-in-stent or parallel stent and in $\mathrm{T}$ or $\mathrm{Y}$ configuration (1B).

\section{Remarks}

When draining both lobes, either $\mathrm{T}$ stent or $\mathrm{Y}$ stent may be deployed. T-stent allows drainage of both lobes through a single access site whereas Y-stent requires two separate access to the bile ducts. ${ }^{151}$ Both techniques are safe and provide effective biliary drainage. ${ }^{174-176}$ Deployment may be simultaneous or sequential and stent-in stent or parallel, with no difference between the techniques. ${ }^{177-180}$

\subsection{Technique for PTBD in benign strictures or bile leaks}

Q45. What is the difference in technique for PTBD in benign strictures or bile leaks?

Benign strictures and bile leaks are associated with minimally dilated or nondilated bile ducts which increase the difficulty of the procedure and complications. There is no difference in the procedural steps of PTBD (1B).

\section{Remarks}

The major group encompassing benign biliary strictures (BBS) includes postoperative anastomotic strictures, typically post LT bile duct stricture, and bilioenteric (hepaticojejunostomy) anastomotic stricture. In the presence of dilated ducts due to benign stricture, no additional challenges are encountered in performing PTBD. However, a good number of patients with benign strictures or and majority with bile leaks, do not show dilated intrahepatic bile ducts. ${ }^{181,182}$ In view of this, obtaining access to the bile ducts requires more skill and experience. Studies have suggested a combination of USG and fluoroscopy as guidance to puncture the bile ducts. ${ }^{183,184}$ The technical success rate of PTBD in nondilated system is in the range of 90 to $100 \% .{ }^{108,185,186}$

Q46. What are the percutaneous methods of treating benign biliary strictures?

Benign strictures are managed by balloon dilatation, serial upgradation to large bore catheters and stents (1B).

\section{Remarks}

No standard protocol has been defined for the management of benign biliary strictures as these are frequently difficult to treat and require long-term and repeated interventions. ${ }^{148.187}$ Percutaneous balloon dilatation is a simple, safe, and effective technique for the treatment of BBS. ${ }^{188}$ A study by Janssen et al suggested that balloon dilatation with long-term drainage resulted in $>85 \%$ clinical success. ${ }^{189}$ Another study by Bonnel and Fingerhut, studying percutaneous balloon dilatation for bilioenteric (hepaticojejunostomy) anastomotic strictures showed a patency of $90.9 \%$ and recurrence rate of $15 \% .{ }^{190}$ Cutting balloons may be used for recalcitrant strictures. ${ }^{191,192}$ Another technique of treatment in post-transplant bile duct strictures is serial upgradation of catheter from $8 \mathrm{~F}$ to 18 to $20 \mathrm{~F}$ which is then left in situ for at least 3 to 6 months. ${ }^{193}$ This 
resulted in primary patency rates of 81 to $89 \%$. Other techniques are the use of covered and biodegradable stents with good results. They have been described in the previous section (Q-39,40). The studies available are retrospective with no randomized controlled trials.

Q47. What is the role of percutaneous biliary intervention in liver transplant patients?

Endoscopic stenting is the preferred option in case of biliary strictures or bile leaks in post-transplant patients; if endoscopic attempt is unsuccessful or there is altered anatomy (bilioenteric anastomosis), percutaneous biliary drainage is the option (1B).

\section{Remarks}

Biliary complications are common (10-25\%) after LT and more common with living donor LT compared with deceased donor LT. ${ }^{194}$ Biliary leak comprises of the majority of post-transplant biliary complications (2-25\%) and is due to anastomotic dehiscence, ischemia, and sphincter of Oddi hypertension. ${ }^{195}$ Biliary strictures usually present late (after 3 months) and can be anastomotic or nonanastomotic. Endoscopic plastic stenting is the preferred treatment option in managing these complications. ${ }^{195}$ However, in cases where bilioenteric anastomosis has been performed (LT in patients with biliary disease like primary sclerosing cholangitis) and in unsuccessful endoscopic attempts, percutaneous biliary drainage is attempted. PTBD is technically challenging as the bile ducts are either nondilated or minimally dilated. Mukund et al, described salvage PTBD in LT patients $(n=32)$ with failed endoscopic approach and showed complete and sustained clinical and biochemical improvement in $82 \%$ of the patients. ${ }^{196}$ The technique failed to resolve sepsis in $18 \%$ of patients. Another study by Jegadeesan et al, evaluating 39 patients who underwent PTBD after failed ERCP for post LT biliary stricture, found PTBD successful in $87 \%$ cases with $15 \%$ morbidity. ${ }^{197}$ Studies have shown that endoscopic stenting has a success rate of 75 to $80 \%$ in biliary complications after LT and PTBD is used as a second line option. ${ }^{198}$

2.13. Brush cytology or brush biopsy in malignant biliary strictures

Q48. What is the role of brush cytology or brush biopsy in cases of malignant biliary strictures?

Intrabiliary brush cytology or biopsy should be obtained whenever possible, particularly when other methods of tissue sampling are not possible or fail $(\mathbf{1 B})$.

\section{Remarks}

Sampling of the endobiliary tissue may be in the form of cytology or biopsy, which may be done by percutaneous or endoscopic route. ${ }^{81}$ The standard fine needle aspiration cytology is less sensitive for small tumors of the biliary system. ${ }^{199}$ Cytology with biopsy is more effective in diagnosis than cytology alone. ${ }^{199}$ The technique involves insertion of a vascular sheath (6F) across the stricture over a wire and then inserting the cytology brush through the sheath followed by repeated movements of the brush at the level of stricture. ${ }^{81}$ The diagnostic sensitivity and specificity of brush cytology are 68 and 100\%, respectively. ${ }^{200,201}$ Forceps biopsy is better than cytology in the diagnosis of malignancy. ${ }^{202,203}$

2.14. Current status of intrabiliary treatment techniques for malignant strictures

Q49. What is the current status of intrabiliary RFA for malignant strictures?

Intrabiliary RFA has been shown to increase the patency rates of biliary stent and may be used (1B).

\section{Remarks}

Biliary RFA uses an over-the-wire bipolar electrode which has been shown to create an ablation zone depth of 1.3 to $4.4 \mathrm{~mm} .{ }^{204}$ In a retrospective study of 50 patients of unresectable malignant biliary obstruction, percutaneous RFA and biliary stent placement were found to be a safe and feasible palliative option. ${ }^{205}$ It has also been shown to improve stent patency. ${ }^{206}$ In patients developing stent obstruction, few short series have shown the benefit of RFA and balloon sweep in recanalization. ${ }^{207-209}$ One recent randomized controlled trial from China showed that endoscopic RFA with stenting significantly increases stent patency and survival in patients with extrahepatic cholangiocarcinoma. ${ }^{210}$

Q50. What is the role of intrabiliary radiation therapy for malignant biliary strictures?

Intrabiliary radiation therapy improves patency of the stent and patient survival (1C).

\section{Remarks}

Two recent retrospective studies have shown that biliary stent with intracavitary radiation with Iodine- 125 particles improves the stent patency and patient survival. ${ }^{211,212}$ Zhou et al showed that, in patients with malignant biliary strictures, stent with I-125 particles had significantly better patency (194d vs. 86d) and overall survival (194d vs. 96d) compared with the control group. ${ }^{212}$ In another large multicenter study by Zhu et al, irradiation stents were associated with lower stent restenosis rate (21 vs. $33 \%$ ) and longer survival (202d vs. 140d) when compared with standard uncovered SEMS. ${ }^{213}$ However, no randomized controlled trials have proven their undisputable benefit.

\subsection{Other methods of biliary drainage and their indications}

Q51. What are the other methods of biliary drainage?

Other methods of biliary drainage include endoscopic drainage, surgical drainage, and endoscopic ultrasound-assisted drainage (1A).

\section{Remarks}

In patients requiring biliary drainage, various approaches include percutaneous, endoscopic, endoscopic ultrasound, and surgical approach. ${ }^{214}$ Surgical method of drainage is associated with higher morbidity and mortality and 
hence is used as a last resort, when other minimally invasive techniques have failed. ${ }^{215}$

Q52. What is the indication for endoscopic drainage and is it better than PTBD?

Endoscopic drainage is suggested as the initial choice in cases of mid and lower bile duct obstruction and with normal upper gastrointestinal anatomy (1A).

\section{Remarks}

Many studies have compared endoscopic and percutaneous biliary drainage in the treatment of malignant biliary strictures. A meta-analysis evaluating three RCTs and 11 retrospective studies compared 2,246 patients who underwent PTBD and 8,100 patients who underwent EBD for malignant obstructive jaundice. ${ }^{216}$ They found no difference between PTBD and EBD in terms of clinical success, complication, and 30-day mortality and suggested that the choice of approach should depend on the level of obstruction, purpose of drainage, and level of expertise. Another meta-analysis comparing both techniques for preoperative drainage in operable hilar cholangiocarcinoma found that PTBD was associated with lower rate of complications (cholangitis and pancreatitis). ${ }^{217}$ These results were also confirmed by another meta-analysis evaluating six trials. ${ }^{25}$

Q53. What is the role of endoscopic ultrasound-guided biliary drainage?

Endoscopic ultrasound-assisted drainage is increasingly being used, but its role is yet to be established (1B).

\section{Remarks}

Endoscopic ultrasound-guided biliary drainage (EUSBD) is increasingly being used in cases where standard endoscopic route fails. ${ }^{218}$ Two recent meta-analysis comparing EUSBD with ERCP-BD found that EUSBD has similar efficacy and safety as ERCP-BD in cases of distal malignant biliary obstruction. ${ }^{219,220}$ An RCT studying 125 patients also confirmed that EUSBD and ERCPBD provide comparable technical and clinical success rates. ${ }^{221}$ However, EUSBD was associated with longer stent patency, lower complications, and more preserved quality of life. A retrospective study comparing EUSBD and PTBD for distal malignant biliary stricture showed that both have similar levels of efficacy. ${ }^{222}$ But, EUSBD had fewer complications and reintervention rates. Similar results were found in another retrospective study by Sharaiha et al. ${ }^{223}$ However, another recent study showed that EUSBD did not offer advantage over PTBD. ${ }^{224}$ Thus EUSBD may be an option in patients with distal biliary obstruction, when ERCP fails, provided the expertise is available. Also, a study has shown that it is better in patients who have ascites. ${ }^{225}$

\section{Q54. When is surgical biliary drainage indicated?}

Surgical drainage is indicated in patients who fail minimally invasive procedures or who need definitive treatment $(1 \mathrm{~A})$.

\section{Remarks}

Surgical method of drainage is associated with higher morbidity and mortality and hence is used as a last resort, when other minimally invasive techniques have failed, in the palliative setting. ${ }^{215}$ However, in patients with resectable tumors, this is the curative treatment of choice. ${ }^{25,217}$

\section{Funding}

None.

\section{Conflict of Interest}

None declared.

\section{References}

1 Sharma MP, Ahuja V. Aetiological spectrum of obstructive jaundice and diagnostic ability of ultrasonography: a clinician's perspective. Trop Gastroenterol 1999;20(4):167-169

2 Yadav A, Condati NK, Mukund A. Percutaneous transhepatic biliary interventions. J Clin Interv Radiol ISVIR 2018;2(1):27-37

3 Bassari R, Koea JB. Jaundice associated pruritis: a review of pathophysiology and treatment. World J Gastroenterol 2015;21(5):1404-1413

4 Kapoor V, Baron RL, Peterson MS. Bile leaks after surgery. AJR Am J Roentgenol 2004;182(2):451-458

5 Ahmad F, Saunders RN, Lloyd GM, Lloyd DM, Robertson GS. An algorithm for the management of bile leak following laparoscopic cholecystectomy. Ann R Coll Surg Engl 2007;89(1):51-56

6 Altman A, Zangan SM. Benign biliary strictures. Semin Intervent Radiol 2016;33(4):297-306

7 Singh A, Gelrud A, Agarwal B. Biliary strictures: diagnostic considerations and approach. Gastroenterol Rep (Oxf 2015;3(1):22-31

8 Lundsgaard-Hansen P. Safe hemoglobin or hematocrit levels in surgical patients. World J Surg 1996;20(9):1182-1188

9 American Society of Anesthesiologists Task Force on Perioperative Blood Transfusion and Adjuvant Therapies. Practice guidelines for perioperative blood transfusion and adjuvant therapies: an updated report by the American Society of Anesthesiologists Task Force on Perioperative Blood Transfusion and Adjuvant Therapies. Anesthesiology 2006;105(1):198-208

10 Patel IJ, Rahim S, Davidson JC, et al. Society of Interventional Radiology Consensus Guidelines for the periprocedural management of thrombotic and bleeding risk in patients undergoing percutaneous image-guided interventions-part II: recommendations: endorsed by the Canadian Association for Interventional Radiology and the Cardiovascular and Interventional Radiological Society of Europe. J Vasc Interv Radiol 2019;30(8):1168-1184.e1

11 Patel IJ, Davidson JC, Nikolic B, et al. Standards of Practice Committee, with Cardiovascular and Interventional Radiological Society of Europe (CIRSE) Endorsement. Consensus guidelines for periprocedural management of coagulation status and hemostasis risk in percutaneous imageguided interventions. J Vasc Interv Radiol 2012;23(6):727-736

12 Madhusudhan KS, Gamanagatti S, Srivastava DN, Gupta AK. Radiological interventions in malignant biliary obstruction. World J Radiol 2016;8(5):518-529

13 Madhusudhan KS, Gamanagatti S, Gupta AK. Imaging and interventions in hilar cholangiocarcinoma: a review. World J Radiol 2015;7(2):28-44 
14 Wu XP, Ni JM, Zhang ZY, et al. Preoperative evaluation of malignant perihilar biliary obstruction: negative-contrast CT cholangiopancreatography and CT angiography versus MRCP and MR angiography. AJR Am J Roentgenol 2015;205(4):780-788

15 Park MS, Kim TK, Kim KW, et al. Differentiation of extrahepatic bile duct cholangiocarcinoma from benign stricture: findings at MRCP versus ERCP. Radiology 2004;233(1):234-240

16 Andersson M, Kostic S, Johansson M, Lundell L, Asztély M, Hellström M. MRI combined with MR cholangiopancreatography versus helical $\mathrm{CT}$ in the evaluation of patients with suspected periampullary tumors: a prospective comparative study. Acta Radiol 2005;46(1):16-27

17 Katabathina VS, Dasyam AK, Dasyam N, Hosseinzadeh K. Adult bile duct strictures: role of MR imaging and MR cholangiopancreatography in characterization. Radiographics 2014;34(3):565-586

18 Girometti R, Cereser L, Bazzocchi M, Zuiani C. Magnetic resonance cholangiography in the assessment and management of biliary complications after OLT. World J Radiol 2014;6(7):424-436

19 Zenouzi R, Welle CL, Venkatesh SK, Schramm C, Eaton JE. Magnetic resonance imaging in primary sclerosing cholangitis-current state and future directions. Semin Liver Dis 2019;39(3):369-380

20 Maurea S, Caleo O, Mollica C, et al. Comparative diagnostic evaluation with MR cholangiopancreatography, ultrasonography and $\mathrm{CT}$ in patients with pancreatobiliary disease. Radiol Med (Torino 2009; 114(3):390-402

21 Min J, Li H, Zhao F, Zhou J. Percutaneous transhepatic biliary drainage vs. endoscopic biliary drainage in periampullary cancer patients undergoing pancreaticoduodenectomy-a systematic review and meta-analysis. Int J Clin Exp Med 2018;11(12):12870-12879

22 Wiggers JK, Coelen RJ, Rauws EA, et al. Preoperative endoscopic versus percutaneous transhepatic biliary drainage in potentially resectable perihilar cholangiocarcinoma (DRAINAGE trial): design and rationale of a randomized controlled trial. BMC Gastroenterol 2015;15:20

23 Moole H, Dharmapuri S, Duvvuri A, et al. Endoscopic versus percutaneous biliary drainage in palliation of advanced malignant hilar obstruction: a meta-analysis and systematic review. Can J Gastroenterol Hepatol 2016;2016:4726078

24 Tang Z, Yang Y, Meng W, Li X. Best option for preoperative biliary drainage in Klatskin tumor: a systematic review and meta-analysis. Medicine (Baltimore 2017;96(43):e8372

25 Liu JG, Wu J, Wang J, et al. Endoscopic biliary drainage versus percutaneous transhepatic biliary drainage in patients with resectable hilar cholangiocarcinoma: a systematic review and meta-analysis. J Laparoendosc Adv Surg Tech A 2018;28(9):1053-1060

26 Hatzidakis A, Venetucci P, Krokidis M, Iaccarino V. Percutaneous biliary interventions through the gallbladder and the cystic duct: what radiologists need to know. Clin Radiol 2014;69(12):1304-1311

27 Gulaya K, Desai SS, Sato K. Percutaneous cholecystostomy: evidence-based current clinical practice. Semin Intervent Radiol 2016;33(4):291-296

28 Gomi H, Solomkin JS, Schlossberg D, et al. Tokyo Guidelines 2018: antimicrobial therapy for acute cholangitis and cholecystitis. J Hepatobiliary Pancreat Sci 2018;25(1):3-16

29 Rhodes A, Evans LE, Alhazzani W, et al. Surviving sepsis campaign: International guidelines for management of sepsis and septic shock: 2016. Intensive Care Med 2017;43(3):304-377

30 van den Hazel SJ, Speelman P, Tytgat GN, Dankert J, van Leeuwen DJ. Role of antibiotics in the treatment and prevention of acute and recurrent cholangitis. Clin Infect Dis $1994 ; 19(2): 279-286$
31 Lee H, Han Y, Kim JR, Kwon W, Kim SW, Jang JY. Preoperative biliary drainage adversely affects surgical outcomes in periampullary cancer: a retrospective and propensity score-matched analysis. J Hepatobiliary Pancreat Sci 2018;25(3):206-213

32 van der Gaag NA, Rauws EA, van Eijck CH, et al. Preoperative biliary drainage for cancer of the head of the pancreas. $\mathrm{N}$ Engl J Med 2010;362(2):129-137

33 Eklund JW, Trifilio S, Mulcahy MF. Chemotherapy dosing in the setting of liver dysfunction. Oncology (Williston Park 2005;19(8):1057-1063, discussion 1063-1064, 1069

34 Covey AM, Brown KT. Percutaneous transhepatic biliary drainage. Tech Vasc Interv Radiol 2008;11(1):14-20

35 Crosara Teixeira M, Mak MP, Marques DF, et al. Percutaneous transhepatic biliary drainage in patients with advanced solid malignancies: prognostic factors and clinical outcomes. J Gastrointest Cancer 2013;44(4):398-403

36 van Delden OM, Laméris JS. Percutaneous drainage and stenting for palliation of malignant bile duct obstruction. Eur Radiol 2008;18(3):448-456

37 Lee SH, Park JK, Yoon WJ, et al. Optimal biliary drainage for inoperable Klatskin's tumor based on Bismuth type. World J Gastroenterol 2007;13(29):3948-3955

38 Paik WH, Loganathan N, Hwang JH. Preoperative biliary drainage in hilar cholangiocarcinoma: When and how? World J Gastrointest Endosc 2014;6(3):68-73

39 Jain MK, Jain R. Acute bacterial cholangitis. Curr Treat Options Gastroenterol 2006;9(2):113-121

40 Bin OY, Zeng KW, Hua HW, Zhang XQ Chen FL. Endoscopic nasobiliary drainage and percutaneous transhepatic biliary drainage for the treatment of acute obstructive suppurative cholangitis: a retrospective study of 37 cases. Hepatogastroenterology 2012;59(120):2454-2456

41 Mukai S, Itoi T, Baron TH, et al. Indications and techniques of biliary drainage for acute cholangitis in updated Tokyo Guidelines 2018. J Hepatobiliary Pancreat Sci 2017;24(10):537-549

42 Talebi-Taher M, Babazadeh S, Barati M, Latifnia M. Serum inflammatory markers in the elderly: are they useful in differentiating sepsis from SIRS? Acta Med Iran 2014;52(6):438-442

43 Liguory C, Vitale GC, Lefebre JF, Bonnel D, Cornud F. Endoscopic treatment of postoperative biliary fistulae. Surgery 1991;110(4):779-783, discussion 783-784

44 Popat B, Thakkar D, Deshmukh H, Rathod K. Percutaneous transhepatic biliary drainage in the management of post-surgical biliary leaks. Indian J Surg 2017;79(1):24-28

45 Zuidema GD, Cameron JL, Sitzmann JV, et al. Percutaneous transhepatic management of complex biliary problems. Ann Surg 1983;197(5):584-593

46 Azeemuddin M, Turab N, Chaudhry MBH, Hamid S, Hasan M, Sayani R. Percutaneous management of biliary enteric anastomotic strictures: an institutional review. Cureus 2018; 10(2):e2228

47 Lee AY, Gregorius J, Kerlan RK Jr, Gordon RL, Fidelman N. Percutaneous transhepatic balloon dilation of biliary-enteric anastomotic strictures after surgical repair of iatrogenic bile duct injuries. PLoS One 2012;7(10):e46478

48 Parsa N, Ichkhanian Y, Khashab MA. Endoscopic retrograde cholangiopancreatography in patients with surgically altered anatomy. Curr Treat Options Gastro 2020;18:212-231

49 De Cobelli F, Marra P, Diana P, Brembilla G, Venturini M. Therapeutic EUS: biliary drainage-the interventional radiologist's perspective. Endosc Ultrasound 2017;6(suppl 3) :S127-S131

50 Malloy PC, Grassi CJ, Kundu S, et al. Standards of Practice Committee with Cardiovascular and Interventional Radiological Society of Europe (CIRSE) Endorsement. Consensus guidelines for periprocedural management of 
coagulation status and hemostasis risk in percutaneous imageguided interventions. J Vasc Interv Radiol 2009;20(suppl 7): S240-S249

51 Gupta P, Maralakunte M, Rathee S, et al. Percutaneous transhepatic biliary drainage in patients at higher risk for adverse events: experience from a tertiary care referral center. Abdom Radiol (NY 2020;45(8):2547-2553

52 Drebes A, de Vos M, Gill S, et al. Prothrombin complex concentrates for coagulopathy in liver disease: single-center, clinical experience in 105 patients. Hepatol Commun 2019;3(4):513-524

53 Lesmana CR, Cahyadinata L, Pakasi LS, Lesmana LA. Efficacy of prothrombin complex concentrate treatment in patients with liver coagulopathy who underwent various invasive hepatobiliary and gastrointestinal procedures. Case Rep Gastroenterol 2016;10(2):315-322

54 Quencer KB, Tadros AS, Marashi KB, et al. Bleeding after percutaneous transhepatic biliary drainage: incidence, causes and treatments. J Clin Med 2018;7(5):94

55 Houghton EJ, Zeledón M, Acquafresca P, Finger C, Palermo M, Giménez ME. Prospective comparison of bleeding complications between right and left approaches in percutaneous biliary drainage. Surg Laparosc Endosc Percutan Tech 2019;29(1):7-12

56 Nikpour AM, Knebel RJ, Cheng D. Diagnosis and management of postoperative biliary leaks. Semin Intervent Radiol 2016;33(4):307-312

57 Mohanty D. Current concepts in platelet transfusion. Asian J Transfus Sci 2009;3(1):18-21

58 Patel V, McLaughlin SW, Shlansky-Goldberg R, et al. Complication rates of percutaneous biliary drainage in the presence of ascites. Abdom Radiol (NY 2019;44(5):1901-1906

59 Sofue K, Arai Y, Takeuchi Y, Fujiwara H, Tokue H, Sugimura K. Safety and efficacy of primary metallic biliary stent placement with tract embolization in patients with massive ascites: a retrospective analysis of 16 patients. J Vasc Interv Radiol 2012;23(4):521-527

60 Duncan C, Hunt SJ, Gade T, Shlansky-Goldberg RD, Nadolski GJ. Outcomes of percutaneous cholecystostomy in the presence of ascites. J Vasc Interv Radiol 2016;27(4):562-6.e1

61 Venara A, Carretier V, Lebigot J, Lermite E. Technique and indications of percutaneous cholecystostomy in the management of cholecystitis in 2014. J Visc Surg 2014;151(6):435-439

62 Anderson JE, Chang DC, Talamini MA. A nationwide examination of outcomes of percutaneous cholecystostomy compared with cholecystectomy for acute cholecystitis, 1998-2010. Surg Endosc 2013;27(9):3406-3411

63 Little MW, Briggs JH, Tapping CR, et al. Percutaneous cholecystostomy: the radiologist's role in treating acute cholecystitis. Clin Radiol 2013;68(7):654-660

64 Akyürek N, Salman B, Yüksel O, et al. Management of acute calculous cholecystitis in high-risk patients: percutaneous cholecystotomy followed by early laparoscopic cholecystectomy. Surg Laparosc Endosc Percutan Tech 2005;15(6):315-320

65 Narayanan S, Keshava SN, Moses V, Ahmed M, Padmanabhan A, Joseph P. Image guided percutaneous cholecystostomy-a single centre experience. J Clin Interv Radiol ISVIR 2020;4(1):20-26

66 Hatzidakis AA, Prassopoulos P, Petinarakis I, et al. Acute cholecystitis in high-risk patients: percutaneous cholecystostomy vs conservative treatment. Eur Radiol 2002;12(7):1778-1784

67 Loozen CS, van Santvoort HC, van Duijvendijk P, et al. Laparoscopic cholecystectomy versus percutaneous catheter drainage for acute cholecystitis in high risk patients (CHOCOLATE): multicentre randomised clinical trial. BMJ 2018;363:k3965

68 Ito K, Fujita N, Noda Y, et al. Percutaneous cholecystostomy versus gallbladder aspiration for acute cholecystitis: a prospective randomized controlled trial. AJR Am J Roentgenol 2004;183(1):193-196

69 Garcés-Albir M, Martín-Gorgojo V, Perdomo R, et al. Acute cholecystitis in elderly and high-risk surgical patients: is percutaneous cholecystostomy preferable to emergency cholecystectomy? J Gastrointest Surg 2020;24(11):2579-2586

70 La Greca A, Di Grezia M, Magalini S, et al. Comparison of cholecystectomy and percutaneous cholecystostomy in acute cholecystitis: results of a retrospective study. Eur Rev Med Pharmacol Sci 2017;21(20):4668-4674

71 Li YL, Wong KH, Chiu KW, et al. Percutaneous cholecystostomy for high-risk patients with acute cholangitis. Medicine (Baltimore 2018;97(19):e0735

72 Patel N, Chick JFB, Gemmete JJ, et al. Interventional radiology-operated cholecystoscopy for the management of symptomatic cholelithiasis: approach, technical success, safety, and clinical outcomes. AJR Am J Roentgenol 2018;210(5):1164-1171

73 Kim YH, Kim YJ, Shin TB. Fluoroscopy-guided percutaneous gallstone removal using a 12-Fr sheath in high-risk surgical patients with acute cholecystitis. Korean J Radiol 2011;12(2):210-215

74 Pomerantz BJ. Biliary tract interventions. Tech Vasc Interv Radiol 2009;12(2):162-170

75 Dewhurst C, Kane RA, Mhuircheartaigh JN, Brook O, Sun M, Siewert B. Complication rate of ultrasound-guided percutaneous cholecystostomy in patients with coagulopathy. AJR Am J Roentgenol 2012;199(6):W753-60

76 Tuite C, Rosenberg EJ. Sedation and analgesia in interventional radiology. Semin Intervent Radiol 2005;22(2):114-120

77 Practice guidelines for preoperative fasting and the use of pharmacologic agents to reduce the risk of pulmonary aspiration: application to healthy patients undergoing elective procedures: an updated report by the American Society of Anesthesiologists Task Force on preoperative fasting and the use of pharmacologic agents to reduce the risk of pulmonary aspiration. Anesthesiology 2017;126(3):376-393

78 Venkatesan AM, Kundu S, Sacks D, et al. Society of Interventional Radiology Standards of Practice Committee. Practice guidelines for adult antibiotic prophylaxis during vascular and interventional radiology procedures. Written by the Standards of Practice Committee for the Society of Interventional Radiology and endorsed by the Cardiovascular Interventional Radiological Society of Europe and Canadian Interventional Radiology Association [corrected]. J Vasc Interv Radiol 2010;21(11):1611-1630, quiz 1631

79 Chehab MA, Thakor AS, Tulin-Silver S, et al. Adult and pediatric antibiotic prophylaxis during vascular and IR procedures: a society of interventional radiology practice parameter update endorsed by the Cardiovascular and Interventional Radiological Society of Europe and the Canadian Association for Interventional Radiology. J Vasc Interv Radiol 2018;29(11):1483-1501.e2

80 Hamada T, Yasunaga H, Nakai Y, et al. Severe bleeding after percutaneous transhepatic drainage of the biliary system: effect of antithrombotic agents-analysis of 34606 cases from a Japanese nationwide administrative database. Radiology 2015;274(2):605-613

81 Ahmed O, Mathevosian S, Arslan B. Biliary interventions: tools and techniques of the trade, access, cholangiography, biopsy, cholangioscopy, cholangioplasty, stenting, stone, and brachytherapy. Semin Intervent Radiol 2016;33(4):283-290

82 Kozlov AV, Polikarpov AA, Oleshchuk NV, Tarazov PG. Comparative assessment of percutaneous transhepatic cholangiodrainage under roentgenoscopy and ultrasound guidance. Vestn Rentgenol Radiol 2002;(4):30-33

83 Nennstiel S, Treiber M, Faber A, et al. Comparison of ultrasound and fluoroscopically guided percutaneous transhepatic biliary drainage. Dig Dis 2019;37(1):77-86 
84 Wagner A, Mayr C, Kiesslich T, Berr F, Friesenbichler P, Wolkersdörfer GW. Reduced complication rates of percutaneous transhepatic biliary drainage with ultrasound guidance. J Clin Ultrasound 2017;45(7):400-407

85 Dietrich CF, Lorentzen T, Appelbaum L, et al. EFSUMB Guidelines on Interventional Ultrasound (INVUS), Part IIIabdominal treatment procedures (long version. Ultraschall Med 2016;37(1):E1-E32

86 Dowsett JF, Vaira D, Hatfield AR, et al. Endoscopic biliary therapy using the combined percutaneous and endoscopic technique. Gastroenterology 1989;96(4):1180-1186

87 De Palma GD, Pezzullo A, Rega M, et al. Unilateral placement of metallic stents for malignant hilar obstruction: a prospective study. Gastrointest Endosc 2003;58(1):50-53

88 Inal M, Akgül E, Aksungur E, Seydaoğlu G. Percutaneous placement of biliary metallic stents in patients with malignant hilar obstruction: unilobar versus bilobar drainage. J Vasc Interv Radiol 2003;14(11):1409-1416

89 Liberato MJ, Canena JM. Endoscopic stenting for hilar cholangiocarcinoma: efficacy of unilateral and bilateral placement of plastic and metal stents in a retrospective review of 480 patients. BMC Gastroenterol 2012;12:103

90 Lee TH, Kim TH, Moon JH, et al. Bilateral versus unilateral placement of metal stents for inoperable high-grade malignant hilar biliary strictures: a multicenter, prospective, randomized study (with video. Gastrointest Endosc 2017;86(5):817-827

91 Nagino M, Takada T, Miyazaki M, et al; Japanese Association of Biliary Surgery; Japanese Society of Hepato-Biliary-Pancreatic Surgery; Japan Society of Clinical Oncology. Preoperative biliary drainage for biliary tract and ampullary carcinomas. J Hepatobiliary Pancreat Surg 2008;15(1):25-30

92 Giurazza F, Corvino F, Contegiacomo A, et al; Italian College of Interventional Radiology (ICIR) Rising Stars Group. Safety and effectiveness of ultrasound-guided percutaneous transhepatic biliary drainage: a multicenter experience. J Ultrasound 2019;22(4):437-445

$93 \mathrm{Kim}$ YH, Cha SJ. US-guided percutaneous transhepatic biliary drainage: comparative study of right-sided and left-sided approach. J Korean Radiol Soc 2002;46(2):115-118

94 Perdue DG, Freeman ML, DiSario JA, et al; ERCP Outcome Study ERCOST Group. Plastic versus self-expanding metallic stents for malignant hilar biliary obstruction: a prospective multicenter observational cohort study. J Clin Gastroenterol 2008;42(9):1040-1046

95 Raju RP, Jaganmohan SR, Ross WA, et al. Optimum palliation of inoperable hilar cholangiocarcinoma: comparative assessment of the efficacy of plastic and self-expanding metal stents. Dig Dis Sci 2011;56(5):1557-1564

96 Born P, Rösch T, Triptrap A, et al. Long-term results of percutaneous transhepatic biliary drainage for benign and malignant bile duct strictures. Scand J Gastroenterol 1998;33(5):544-549

97 Keshava SN, Mammen S. Percutaneous placement of a biliary plastic stent. Indian J Radiol Imaging 2011;21(3):231-233

98 Blanco PA, Do Pico JJ. Ultrasound-guided percutaneous cholecystostomy in acute cholecystitis: case vignette and review of the technique. J Ultrasound 2015;18(4):311-315

99 Beland MD, Patel L, Ahn SH, Grand DJ. Image-guided cholecystostomy tube placement: short- and long-term outcomes of transhepatic versus transperitoneal placement. AJR Am J Roentgenol 2019;212(1):201-204

100 Katabathina VS, Zafar AM, Suri R. Clinical presentation, imaging, and management of acute cholecystitis. Tech Vasc Interv Radiol 2015;18(4):256-265

101 Loberant N, Notes Y, Eitan A, Yakir O, Bickel A. Comparison of early outcome from transperitoneal versus transhepatic percutaneous cholecystostomy. Hepatogastroenterology 2010;57(97):12-17
102 Ginat D, Saad WEA. Cholecystostomy and transcholecystic biliary access. Tech Vasc Interv Radiol 2008;11(1):2-13

103 Schmassmann A, von Gunten E, Knuchel J, Scheurer U, Fehr HF, Halter F. Wallstents versus plastic stents in malignant biliary obstruction: effects of stent patency of the first and second stent on patient compliance and survival. Am J Gastroenterol 1996;91(4):654-659

104 Zhang GY, Li WT, Peng WJ, Li GD, He XH, Xu LC. Clinical outcomes and prediction of survival following percutaneous biliary drainage for malignant obstructive jaundice. Oncol Lett 2014;7(4):1185-1190

105 Thornton RH, Ulrich R, Hsu M, et al. Outcomes of patients undergoing percutaneous biliary drainage to reduce bilirubin for administration of chemotherapy. J Vasc Interv Radiol 2012;23(1):89-95

106 Robson PC, Heffernan N, Gonen M, et al. Prospective study of outcomes after percutaneous biliary drainage for malignant biliary obstruction. Ann Surg Oncol 2010;17(9):2303-2311

107 van Lent AU, Bartelsman JF, Tytgat GN, Speelman P, Prins JM. Duration of antibiotic therapy for cholangitis after successful endoscopic drainage of the biliary tract. Gastrointest Endosc 2002;55(4):518-522

108 de Jong EA, Moelker A, Leertouwer T, Spronk S, Van Dijk M, van Eijck $\mathrm{CH}$. Percutaneous transhepatic biliary drainage in patients with postsurgical bile leakage and nondilated intrahepatic bile ducts. Dig Surg 2013;30(4-6):444-450

109 Barkay O, Mosler P, Schmitt CM, et al. Effect of endoscopic stenting of malignant bile duct obstruction on quality of life. J Clin Gastroenterol 2013;47(6):526-531

110 Gamanagatti S, Singh T, Sharma R, Srivastava DN, Dash NR, Garg PK. Unilobar versus bilobar biliary drainage: effect on quality of life and bilirubin level reduction. Indian J Palliat Care 2016;22(1):50-62

111 Rees J, Mytton J, Evison F, Mangat KS, Patel P, Trudgill N. The outcomes of biliary drainage by percutaneous transhepatic cholangiography for the palliation of malignant biliary obstruction in England between 2001 and 2014: a retrospective cohort study. BMJ Open 2020;10(1):e033576

112 Nennstiel S, Weber A, Frick G, et al. Drainage-related complications in percutaneous transhepatic biliary drainage: an analysis over 10 years. J Clin Gastroenterol 2015;49(9):764-770

113 Morita S, Kitanosono T, Lee D, et al. Comparison of technical success and complications of percutaneous transhepatic cholangiography and biliary drainage between patients with and without transplanted liver. AJR Am J Roentgenol 2012;199(5):1149-1152

114 Liu YS, Lin CY, Chuang MT, Tsai YS, Wang CK, Ou MC. Success and complications of percutaneous transhepatic biliary drainage are influenced by liver entry segment and level of catheter placement. Abdom Radiol (NY 2018;43(3):713-722

115 Nomura T, Shirai Y, Hatakeyama K. Bacteribilia and cholangitis after percutaneous transhepatic biliary drainage for malignant biliary obstruction. Dig Dis Sci 1999;44(3):542-546

116 Rösch T, Triptrap A, Born P, et al. Bacteriobilia in percutaneous transhepatic biliary drainage: occurrence over time and clinical sequelae. A prospective observational study. Scand J Gastroenterol 2003;38(11):1162-1168

117 Saad WE, Wallace MJ, Wojak JC, Kundu S, Cardella JF. Quality improvement guidelines for percutaneous transhepatic cholangiography, biliary drainage, and percutaneous cholecystostomy. J Vasc Interv Radiol 2010;21(6):789-795

118 Lucatelli P, Corradini SG, Corona M, et al. Risk factors for immediate and delayed-onset fever after percutaneous transhepatic biliary drainage. Cardiovasc Intervent Radiol 2016;39(5):746-755

119 Weber A, Gaa J, Rosca B, et al. Complications of percutaneous transhepatic biliary drainage in patients with 
dilated and nondilated intrahepatic bile ducts. Eur J Radiol 2009;72(3):412-417

120 Cohan RH, Illescas FF, Saeed M, et al. Infectious complications of percutaneous biliary drainage. Invest Radiol 1986;21(9):705-709

121 Miura F, Okamoto K, Takada T, et al. Tokyo Guidelines 2018: initial management of acute biliary infection and flowchart for acute cholangitis. J Hepatobiliary Pancreat Sci 2018;25(1):31-40

122 Garcarek J, Kurcz J, Guziński M, Janczak D, Sasiadek M. Ten years single center experience in percutaneous transhepatic decompression of biliary tree in patients with malignant obstructive jaundice. Adv Clin Exp Med 2012;21(5):621-632

123 Mueller PR, van Sonnenberg E, Ferrucci JT Jr. Percutaneous biliary drainage: technical and catheter-related problems in 200 procedures. AJR Am J Roentgenol 1982;138(1):17-23

124 Ginat D, Saad WE, Davies MG, Saad NE, Waldman DL, Kitanosono T. Incidence of cholangitis and sepsis associated with percutaneous transhepatic biliary drain cholangiography and exchange: a comparison between liver transplant and native liver patients. AJR Am J Roentgenol 2011;196(1):W73-7

125 Günther RW, Schild H, Thelen M. Percutaneous transhepatic biliary drainage: experience with 311 procedures. Cardiovasc Intervent Radiol 1988;11(2):65-71

126 Venkatanarasimha N, Damodharan K, Gogna A, et al. Diagnosis and management of complications from percutaneous biliary tract interventions. Radiographics 2017;37(2):665-680

127 Sutter CM, Ryu RK. Percutaneous management of malignant biliary obstruction. Tech Vasc Interv Radiol 2015;18(4):218-226

128 Hatzidakis AA, Charonitakis E, Athanasiou A, et al. Sedations and analgesia in patients undergoing percutaneous transhepatic biliary drainage. Clin Radiol 2003;58(2):121-127

129 Culp WC, McCowan TC, DeValdenebro M. Wright LB, Workman JL, Culp WC Jr. Paravertebral block: an improved method of pain control in percutaneous transhepatic biliary drainage. Cardiovasc Intervent Radiol 2006;29(6):1015-1021

130 Hsien-Tzu L, Hsiuo Shan T, Nai Chi C, Yi Yang L, Yi You C, Chien An L. Percutaneous transhepatic techniques for retrieving fractured and intrahepatically dislodged percutaneous transhepatic biliary drainage catheters. Diagn Interv Radiol 2017;23(6):461-464

131 Saad WEA, Davies MG, Darcy MD. Management of bleeding after percutaneous transhepatic cholangiography or transhepatic biliary drain placement. Tech Vasc Interv Radiol 2008;11(1):60-71

132 Choi SH, Gwon DI, Ko GY, et al. Hepatic arterial injuries in 3110 patients following percutaneous transhepatic biliary drainage. Radiology 2011;261(3):969-975

133 Fidelman N, Bloom AI, Kerlan RK Jr, et al. Hepatic arterial injuries after percutaneous biliary interventions in the era of laparoscopic surgery and liver transplantation: experience with 930 patients. Radiology 2008;247(3):880-886

134 Deipolyi AR, Covey AM. Palliative percutaneous biliary interventions in malignant high bile duct obstruction. Semin Intervent Radiol 2017;34(4):361-368

135 Chanyaputhipong J, Lo RH, Tan BS, Chow PK. Portobiliary fistula: successful transcatheter treatment with embolisation coils. Singapore Med J 2014;55(3):e34-e36

136 Madhusudhan KS, Dash NR, Afsan A, Gamanagatti S, Srivastava DN, Gupta AK. Delayed severe hemobilia due to bilio-venous fistula after percutaneous transhepatic biliary drainage: treatment with covered stent placement. J Clin Exp Hepatol 2016;6(3):241-243

137 Lynskey GE, Banovac F, Chang T. Vascular complications associated with percutaneous biliary drainage: a report of three cases. Semin Intervent Radiol 2007;24(3):316-319

138 Madhusudhan KS, Venkatesh HA, Gamanagatti S, Garg P, Srivastava DN. Interventional radiology in the management of visceral artery pseudoaneurysms: a review of techniques and embolic materials. Korean J Radiol 2016;17(3):351-363

139 Al-Bahrani AZ, Holt A, Hamade AM, et al. Acute pancreatitis: an under-recognized risk of percutaneous transhepatic distal biliary intervention. HPB (Oxford 2006;8(6):446-450

140 Khosla A, Xi Y, Toomay S. Predicting success in percutaneous transhepatic biliary drainage. Cardiovasc Intervent Radiol 2017;40(10):1586-1592

141 Yeo CS, Tay VW, Low JK, Woon WW, Punamiya SJ, Shelat VG. Outcomes of percutaneous cholecystostomy and predictors of eventual cholecystectomy. J Hepatobiliary Pancreat Sci 2016;23(1):65-73

142 vanSonnenberg E, D'Agostino HB, Goodacre BW, Sanchez RB, Casola G. Percutaneous gallbladder puncture and cholecystostomy: results, complications, and caveats for safety. Radiology 1992;183(1):167-170

143 Yasumoto T, Yokoyama S, Nagaike K. Percutaneous transcholecystic metallic stent placement for malignant obstruction of the common bile duct: preliminary clinical evaluation. J Vasc Interv Radiol 2010;21(2):252-258

144 Chou CK, Lee KC, Chan CC, et al. Early percutaneous cholecystostomy in severe acute cholecystitis reduces the complication rate and duration of hospital stay. Medicine (Baltimore 2015;94(27):e1096

145 Winbladh A, Gullstrand P, Svanvik J, Sandström P. Systematic review of cholecystostomy as a treatment option in acute cholecystitis. HPB (Oxford 2009;11(3):183-193

146 England RE, McDermott VG, Smith TP, Suhocki PV, Payne CS, Newman GE. Percutaneous cholecystostomy: who responds? AJR Am J Roentgenol 1997;168(5):1247-1251

147 Sanjay P, Mittapalli D, Marioud A, White RD, Ram R, Alijani A. Clinical outcomes of a percutaneous cholecystostomy for acute cholecystitis: a multicentre analysis. HPB (Oxford 2013;15(7):511-516

148 Kapoor BS, Mauri G, Lorenz JM. Management of biliary strictures: state-of-the-art review. Radiology 2018;289(3):590-603

149 Yeoh KG, Zimmerman MJ, Cunningham JT, Cotton PB, Comparative costs of metal versus plastic biliary stent strategies for malignant obstructive jaundice by decision analysis. Gastrointest Endosc 1999;49(4 Pt 1) :466-471

150 Maybody M, Brown KT, Brody LA, et al. Primary patency of Wallstents in malignant bile duct obstruction: single vs. two or more noncoaxial stents. Cardiovasc Intervent Radiol 2009;32(4):707-713

151 Shim DJ, Gwon DI, Han K, et al. Percutaneous metallic stent placement for palliative management of malignant biliary hilar obstruction. Korean J Radiol 2018;19(4):597-605

152 Fu YF, Zhou WJ, Shi YB, Cao W, Cao C. Percutaneous stenting for malignant hilar biliary obstruction: a randomized controlled trial of unilateral versus bilateral stenting. Abdom Radiol (NY 2019;44(8):2900-2908

153 Aghaie Meybodi M, Shakoor D, Nanavati J, et al. Unilateral versus bilateral endoscopic stenting in patients with unresectable malignant hilar obstruction: a systematic review and meta-analysis. Endosc Int Open 2020;8(3):E281-E290

154 Kahaleh M, Behm B, Clarke BW, et al. Temporary placement of covered self-expandable metal stents in benign biliary strictures: a new paradigm? (with video. Gastrointest Endosc 2008;67(3):446-454

$155 \mathrm{Kim} \mathrm{JH}$, Gwon DI, Ko GY, et al. Temporary placement of retrievable fully covered metallic stents versus percutaneous balloon dilation in the treatment of benign biliary strictures. J Vasc Interv Radiol 2011;22(6):893-899

156 Gwon DI, Ko GY, Ko HK, Yoon HK, Sung KB. Percutaneous transhepatic treatment using retrievable covered stents in patients with benign biliary strictures: mid-term outcomes in 68 patients. Dig Dis Sci 2013;58(11):3270-3279 
157 Mauri G, Michelozzi C, Melchiorre F, et al. Biodegradable biliary stent implantation in the treatment of benign bilioplastic-refractory biliary strictures: preliminary experience. Eur Radiol 2013;23(12):3304-3310

158 Mauri G, Michelozzi C, Melchiorre F, et al. Benign biliary strictures refractory to standard bilioplasty treated using polydoxanone biodegradable biliary stents: retrospective multicentric data analysis on 107 patients. Eur Radiol 2016;26(11):4057-4063

159 Almadi MA, Barkun AN, Martel M. No benefit of covered vs uncovered self-expandable metal stents in patients with malignant distal biliary obstruction: a meta-analysis. Clin Gastroenterol Hepatol 2013;11(1):27-37.e1

160 Kullman E, Frozanpor F, Söderlund C, et al. Covered versus uncovered self-expandable nitinol stents in the palliative treatment of malignant distal biliary obstruction: results from a randomized, multicenter study. Gastrointest Endosc 2010;72(5):915-923

161 Moole H, Bechtold ML, Cashman M, et al. Covered versus uncovered self-expandable metal stents for malignant biliary strictures: a meta-analysis and systematic review. Indian J Gastroenterol 2016;35(5):323-330

162 Loew BJ, Howell DA, Sanders MK, et al. Comparative performance of uncoated, self-expanding metal biliary stents of different designs in 2 diameters: final results of an international multicenter, randomized, controlled trial. Gastrointest Endosc 2009;70(3):445-453

163 Yun G, Yoon CJ, Seong NJ. Percutaneous treatment of benign bilioenteric anastomotic strictures: temporary covered stent placement versus balloon dilatation. Eur Radiol 2019;29(5):2690-2697

164 G Almeida G, Donato P. Biodegradable versus multiple plastic stent implantation in benign biliary strictures: a systematic review and meta-analysis. Eur J Radiol 2020;125:108899

165 Song TJ, Lee SS, Yun SC, et al. Paclitaxel-eluting covered metal stents versus covered metal stents for distal malignant biliary obstruction: a prospective comparative pilot study. Gastrointest Endosc 2011;73(4):727-733

166 Jang SI, Kim JH, You JW, et al. Efficacy of a metallic stent covered with a paclitaxel-incorporated membrane versus a covered metal stent for malignant biliary obstruction: a prospective comparative study. Dig Dis Sci 2013;58(3):865-871

167 Inal M, Aksungur E, Akgül E, Oguz M, Seydaoglu G. Percutaneous placement of metallic stents in malignant biliary obstruction: one-stage or two-stage procedure? Pre-dilate or not? Cardiovasc Intervent Radiol 2003;26(1):40-45

168 Chatzis N, Pfiffner R, Glenck M, Stolzmann P, Pfammatter T, Sharma P. Comparing percutaneous primary and secondary biliary stenting for malignant biliary obstruction: a retrospective clinical analysis. Indian J Radiol Imaging 2013;23(1):38-45

169 Shen ZY, Wang JJ, Lu LG, Wan R, Wan XJ, Cai XB. The efficacy and safety of balloon dilation for unresectable malignant biliary obstruction before placement of self-expanding metal stents. J Dig Dis 2020;21(5):293-300

170 Cosgrove N, Siddiqui AA, Adler DG, et al. A comparison of bilateral side-by-side metal stents deployed above and across the sphincter of Oddi in the management of malignant hilar biliary obstruction. J Clin Gastroenterol 2017;51(6):528-533

171 Jo JH, Park BH. Suprapapillary versus transpapillary stent placement for malignant biliary obstruction: which is better. ? J Vasc Interv Radiol 2015;26(4):573-582

172 Bakhru M, Ho HC, Gohil V, et al. Fully-covered, self-expandable metal stents (CSEMS) in malignant distal biliary strictures: mid-term evaluation. J Gastroenterol Hepatol 2011;26(6):1022-1027

173 Shin J, Park JS, Jeong S, Lee DH. Comparison of the clinical outcomes of suprapapillary and transpapillary stent insertion in unresectable cholangiocarcinoma with biliary obstruction. Dig Dis Sci 2020;65(4):1231-1238

174 Li TF, Li Z, Han XW, et al. Combined T/Y biliary stent placement for the treatment of biliary obstruction caused by Bismuth-Corlett type IV hilar cholangiocarcinoma. Hepatogastroenterology 2014;61(134):1519-1522

175 Gwon DI, Ko GY, Kim JH, et al. Percutaneous bilateral metallic stent placement using a stentin-stent deployment technique in patients with malignant hilar biliary obstruction. AJR Am J Roentgenol 2013;200(4):909-914

176 Gwon DI, Ko GY, Yoon HK, et al. Safety and efficacy of percutaneous Y-configured covered stent placement for malignant hilar biliary obstruction: a prospective, pilot study. J Vasc Interv Radiol 2012;23(4):528-534

177 Law R, Baron TH. Bilateral metal stents for hilar biliary obstruction using a 6Fr delivery system: outcomes following bilateral and side-by-side stent deployment. Dig Dis Sci 2013;58(9):2667-2672

178 Naitoh I, Hayashi K, Nakazawa T, et al. Side-by-side versus stent-in-stent deployment in bilateral endoscopic metal stenting for malignant hilar biliary obstruction. Dig Dis Sci 2012;57(12):3279-3285

179 Inoue T, Ishii N, Kobayashi Y, et al. Simultaneous versus sequential side-by-side bilateral metal stent placement for malignant hilar biliary obstructions. Dig Dis Sci 2017;62(9):2542-2549

180 Kim KM, Lee KH, Chung YH, et al. A comparison of bilateral stenting methods for malignant hilar biliary obstruction. Hepatogastroenterology 2012;59(114):341-346

181 Keogan MT, McDermott VG, Price SK, Low VH, Baillie J. The role of imaging in the diagnosis and management of biliary complications after liver transplantation. AJR Am J Roentgenol 1999;173(1):215-219

182 Pedicini V, Poretti D, Mauri G, et al. Management of post-surgical biliary leakage with percutaneous transhepatic biliary drainage (PTBD) and occlusion balloon $(\mathrm{OB})$ in patients without dilatation of the biliary tree: preliminary results. Eur Radiol 2010;20(5):1061-1068

183 Shimizu H, Kato A, Takayashiki T, et al. Peripheral portal vein-oriented non-dilated bile duct puncture for percutaneous transhepatic biliary drainage. World J Gastroenterol 2015;21(44):12628-12634

184 Lee W, Kim GC, Kim JY, et al. Ultrasound and fluoroscopy guided percutaneous transhepatic biliary drainage in patients with nondilated bile ducts. Abdom Imaging 2008;33(5):555-559

185 Cozzi G, Severini A, Civelli E, et al. Percutaneous transhepatic biliary drainage in the management of postsurgical biliary leaks in patients with nondilated intrahepatic bile ducts. Cardiovasc Intervent Radiol 2006;29(3):380-388

186 Righi D, Franchello A, Ricchiuti A, et al. Safety and efficacy of the percutaneous treatment of bile leaks in hepaticojejunostomy or split-liver transplantation without dilatation of the biliary tree. Liver Transpl 2008;14(5):611-615

187 Fidelman N. Benign biliary strictures: diagnostic evaluation and approaches to percutaneous treatment. Tech Vasc Interv Radiol 2015;18(4):210-217

188 Cantwell CP, Pena CS, Gervais DA, Hahn PF, Dawson SL, Mueller PR. Thirty years' experience with balloon dilation of benign postoperative biliary strictures: long-term outcomes. Radiology 2008;249(3):1050-1057

189 Janssen JJ, van Delden OM, van Lienden KP, et al. Percutaneous balloon dilatation and long-term drainage as treatment of anastomotic and nonanastomotic benign biliary strictures. Cardiovasc Intervent Radiol 2014;37(6):1559-1567

190 Bonnel DH, Fingerhut AL. Percutaneous transhepatic balloon dilatation of benign bilioenteric strictures: long-term results in 110 patients. Am J Surg 2012;203(6):675-683

191 Saad WE, Davies MG, Saad NE, et al. Transhepatic dilation of anastomotic biliary strictures in liver transplant recipients 
with use of a combined cutting and conventional balloon protocol: technical safety and efficacy. J Vasc Interv Radiol 2006;17(5):837-843

192 Mukund A, Rajesh S, Agrawal N, Arora A, Arora A. Percutaneous management of resistant biliary-enteric anastomotic strictures with the use of a combined cutting and conventional balloon cholangioplasty protocol: a single-center experience. J Vasc Interv Radiol 2015;26(4):560-565

193 Ludwig JM, Webber GR, Knechtle SJ, Spivey JR, Xing M, Kim HS. Percutaneous management of benign biliary strictures with large-bore catheters: comparison between patients with and without orthotopic liver transplantation. J Vasc Interv Radiol 2016;27(2):219-225.e1

194 Moy BT, Birk JW. A review on the management of biliary complications after orthotopic liver transplantation. J Clin Transl Hepatol 2019;7(1):61-71

195 Kochhar G, Parungao JM, Hanouneh IA, Parsi MA. Biliary complications following liver transplantation. World J Gastroenterol 2013;19(19):2841-2846

196 Mukund A, Choudhury A, Das S, Pamecha V, Sarin SK. Salvage PTBD in post living donor liver transplant patients with biliary complications-a single centre retrospective study. Br J Radiol 2020;93(1108):20191046

197 Jegadeesan M, Goyal N, Rastogi H, Gupta S. Percutaneous transhepatic biliary drainage for biliary stricture after endotherapy failure in living donor liver transplantation: a single-centre experience from India. J Clin Exp Hepatol 2019;9(6):684-689

198 Wadhawan M, Kumar A. Management issues in post living donor liver transplant biliary strictures. World J Hepatol 2016;8(10):461-470

199 Jung GS, Huh JD, Lee SU, Han BH, Chang HK, Cho YD. Bile duct: analysis of percutaneous transluminal forceps biopsy in 130 patients suspected of having malignant biliary obstruction. Radiology 2002;224(3):725-730

200 Govil H, Reddy V, Kluskens L, et al. Brush cytology of the biliary tract: retrospective study of 278 cases with histopathologic correlation. Diagn Cytopathol 2002;26(5):273-277

201 Navaneethan U, Njei B, Lourdusamy V, Konjeti R, Vargo JJ, Parsi MA. Comparative effectiveness of biliary brush cytology and intraductal biopsy for detection of malignant biliary strictures: a systematic review and meta-analysis. Gastrointest Endosc 2015;81(1):168-176

202 Yamamoto K, Tsuchiya T, Itoi T, et al. Evaluation of novel slim biopsy forceps for diagnosis of biliary strictures: single-institutional study of consecutive 360 cases (with video. World J Gastroenterol 2017;23(35):6429-6436

203 Fohlen A, Bazille C, Menahem B, et al. Transhepatic forceps biopsy combined with biliary drainage in obstructive jaundice: safety and accuracy. Eur Radiol 2019;29(5):2426-2435

204 Itoi T, Isayama H, Sofuni A, et al. Evaluation of effects of a novel endoscopically applied radiofrequency ablation biliary catheter using an ex-vivo pig liver. J Hepatobiliary Pancreat Sci 2012;19(5):543-547

205 Cui W, Fan W, Lu M, et al. The safety and efficacy of percutaneous intraductal radiofrequency ablation in unresectable malignant biliary obstruction: a single-institution experience. BMC Cancer 2017;17(1):288

206 Li TF, Huang GH, Li Z, et al. Percutaneous transhepatic cholangiography and intraductal radiofrequency ablation combined with biliary stent placement for malignant biliary obstruction. J Vasc Interv Radiol 2015;26(5):715-721

207 Pai M, Valek V, Tomas A, et al. Percutaneous intraductal radiofrequency ablation for clearance of occluded metal stent in malignant biliary obstruction: feasibility and early results. Cardiovasc Intervent Radiol 2014;37(1):235-240

208 Xia N, Gong J, Lu J, Chen ZJ, Zhang LY, Wang ZM. Percutaneous intraductal radiofrequency ablation for treatment of biliary stent occlusion: a preliminary result. World J Gastroenterol 2017;23(10):1851-1856

209 Betgeri S, Rajesh S, Arora A, Panda D, Bhadoria AS, Mukund A. Percutaneous endobiliary RFA combined with balloon-sweep for re-opening occluded metallic biliary stents. Minim Invasive Ther Allied Technol 2017;26(2):124-127

210 Yang J, Wang J, Zhou H, et al. Efficacy and safety of endoscopic radiofrequency ablation for unresectable extrahepatic cholangiocarcinoma: a randomized trial. Endoscopy 2018;50(8):751-760

211 Pang Q, Zhou L, Hu XS, et al. Biliary stenting alone versus biliary stenting combined with 125 I particles intracavitary irradiation for the treatment of advanced cholangiocarcinoma. Sci Rep 2019;9(1):11348

212 Zhou WZ, Fu YM, Yang ZQ et al. Study of percutaneous stent placement with Iodine-125 seed strand for malignant biliary obstruction. Cardiovasc Intervent Radiol 2019;42(2):268-275

213 Zhu HD, Guo JH, Huang M, et al. Irradiation stents vs. conventional metal stents for unresectable malignant biliary obstruction: a multicenter trial. J Hepatol 2018;68(5):970-977

214 Lorenz JM. Management of malignant biliary obstruction. Semin Intervent Radiol 2016;33(4):259-267

215 Arshad SA, Phuoc VH. Surgical palliation of biliary obstruction: bypass in the era of drainage. J Surg Oncol 2019;120(1):65-66

216 Duan F, Cui L, Bai Y, Li X, Yan J, Liu X. Comparison of efficacy and complications of endoscopic and percutaneous biliary drainage in malignant obstructive jaundice: a systematic review and meta-analysis. Cancer Imaging 2017;17(1):27

217 Al Mahjoub A, Menahem B, Fohlen A, et al. Preoperative biliary drainage in patients with resectable perihilar cholangiocarcinoma: is percutaneous transhepatic biliary drainage safer and more effective than endoscopic biliary drainage? A meta-analysis. J Vasc Interv Radiol 2017;28(4):576-582

218 Mishra A, Tyberg A. Endoscopic ultrasound guided biliary drainage: a comprehensive review. Transl Gastroenterol Hepatol 2019;4:10

219 Jin Z, Wei Y, Lin H, et al. Endoscopic ultrasound-guided versus endoscopic retrograde cholangiopancreatography-guided biliary drainage for primary treatment of distal malignant biliary obstruction: a systematic review and meta-analysis. Dig Endosc 2020;32(1):16-26

220 Hathorn KE, Bazarbashi AN, Sack JS, et al. EUS-guided biliary drainage is equivalent to ERCP for primary treatment of malignant distal biliary obstruction: a systematic review and meta-analysis. Endosc Int Open 2019;7(11):E1432-E1441

221 Paik WH, Lee TH, Park DH, et al. EUS-guided biliary drainage versus ERCP for the primary palliation of malignant biliary obstruction: a multicenter randomized clinical trial. Am J Gastroenterol 2018;113(7):987-997

222 Lee TH, Choi JH, Park H, et al. Similar efficacies of endoscopic ultrasound-guided transmural and percutaneous drainage for malignant distal biliary obstruction. Clin Gastroenterol Hepatol 2016;14(7):1011-1019.e3

223 Sharaiha RZ, Kumta NA, Desai AP, et al. Endoscopic ultrasound-guided biliary drainage versus percutaneous transhepatic biliary drainage: predictors of successful outcome in patients who fail endoscopic retrograde cholangiopancreatography. Surg Endosc 2016;30(12):5500-5505

224 Lesmana CRA, Gani RA, Hasan I, et al. Palliative endoscopic ultrasound biliary drainage for advanced malignant biliary obstruction: should it replace the percutaneous approach? Case Rep Gastroenterol 2019;13(3):385-397

225 Alvarez-Sánchez MV, Luna OB, Oria I, et al. Feasibility and Safety of Endoscopic Ultrasound-Guided Biliary Drainage (EUS-BD) for malignant biliary obstruction associated with ascites: results of a pilot study. J Gastrointest Surg 2018;22(7):1213-1220 